\title{
Implementing incipient actions: The discourse marker 'so' in English conversation
}

\author{
Galina B. Bolden \\ Department of Communication, Rutgers University, 4 Huntington Street, New Brunswick, NJ 08901, United States
}

Received 7 May 2007; received in revised form 22 May 2008; accepted 2 October 2008

\begin{abstract}
The discourse marker 'so' is most commonly described as indexing inferential or causal connections. However, recordings of everyday talk show that these are not its only functions. The article uses the methodology of conversation analysis and examines a large corpus of recorded conversations to explicate the role of 'so' in implementing incipient actions. The analysis focuses on the use of 'so' for prefacing sequence-initiating actions (such as questions) and demonstrates that speakers deploy this preface to indicate the status of the upcoming action as 'emerging from incipiency' rather than being contingent on the immediately preceding talk. 'So' prefacing is recurrently used in contexts where the activity being launched has been relevantly pending. Additionally, speakers can use 'so' to characterize and constitute a particular action as advancing their interactional agenda. The article shows that this marker is a resource for establishing discourse coherence and, more fundamentally, accomplishing understanding.
\end{abstract}

(C) 2008 Elsevier B.V. All rights reserved.

Keywords: Discourse markers; Conversation analysis

\section{Introduction}

This article examines pragmatic functions of the English discourse marker 'so' in conversational speech. Most prior - surprisingly scarce - research on 'so' has focused on its use for marking inferential or causal connections between clauses. Yet, 'so' can be used for other purposes as well, as evidenced in the following dictionary entries:

said in order to get someone's attention, especially in order to ask him/her a question: So, what do you think of the school? (Longman Dictionary of American English, 1983:766) in conversations to introduce a new topic: So how was your day? (Collins COBUILD English Dictionary, 1995:1581-1582)

These readily recognizable examples can be easily supplemented by recorded instances, such as the following from a telephone conversation ${ }^{1}$ :

Excerpt 1: CallFriend 5051

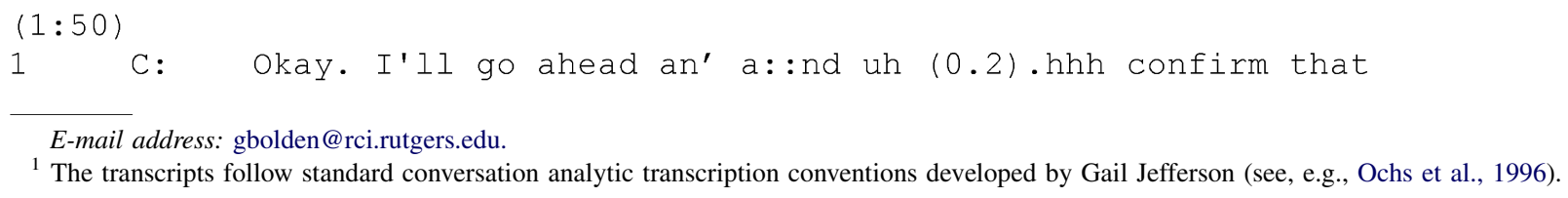

E-mail address: gbolden@rci.rutgers.edu.

${ }^{1}$ The transcripts follow standard conversation analytic transcription conventions developed by Gail Jefferson (see, e.g., Ochs et al., 1996). 


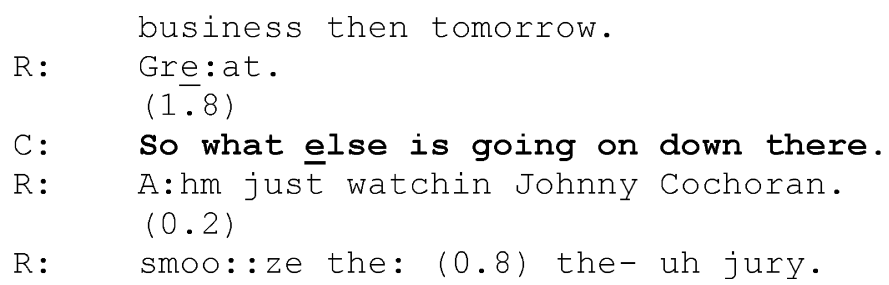

Illustrations like these suggest that aside for marking causal relationships, 'so' is recurrently deployed for other interactional purposes. The aim of this article is to elucidate what these purposes are.

What seems to distinguish the usages of 'so' illustrated above from inferential ones is the sequential environment of their deployment. As alluded to in the dictionary entries and evidenced in the recorded excerpt above, the discourse marker is most commonly used to mark something other than causal connections when it prefaces turn constructional units (or TCUs) ${ }^{2}$ that implement sequence-initiating actions (i.e., first pair parts in adjacency pair sequences, ${ }^{3}$ such as, questions) and that accomplish a shift to a new conversational activity. Conversely, 'so' commonly carries inferential meaning in a variety of other, sequence or activity-internal environments, ${ }^{4}$ as illustrated by the following excerpt. Here Hyla formulates her plans for getting to the theater on time - plans that are contingent on the play's starting time (lines 2-3):

Excerpt 2: HG IIa

$(6: 35)$

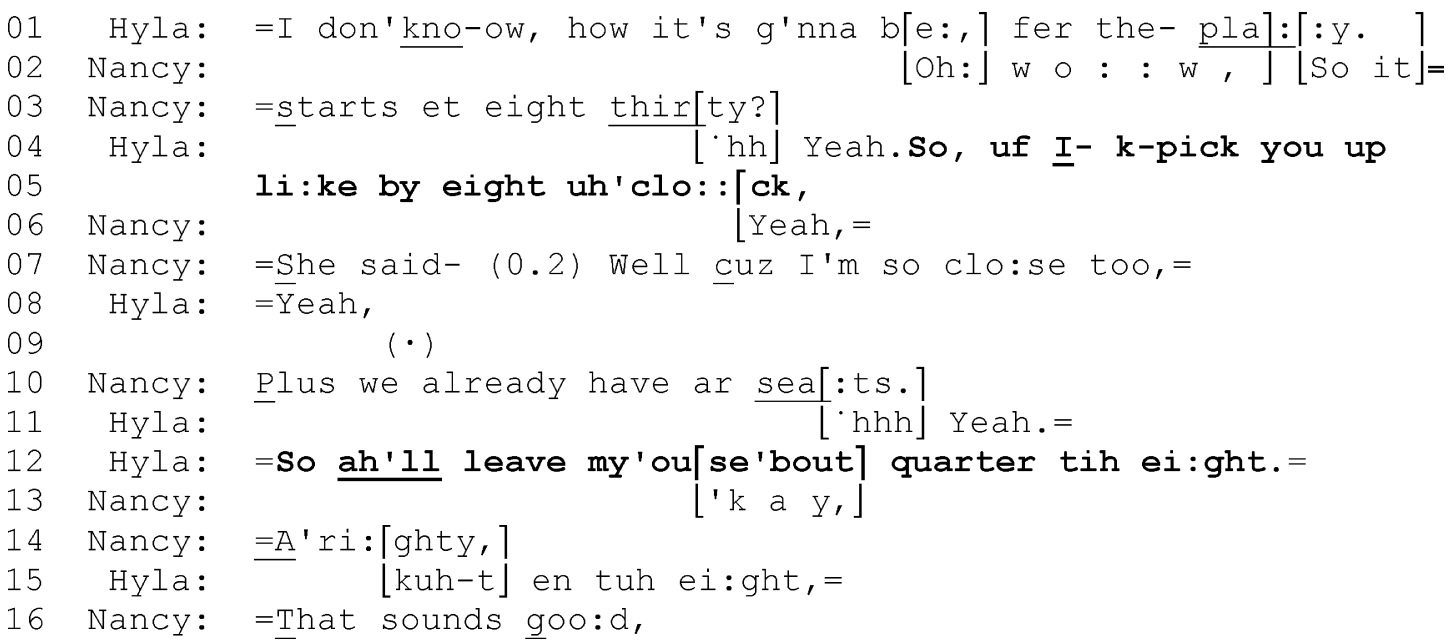

Hyla's two 'so'-prefaced turn constructional units (lines 4-5 and 12) formulate her actions as resulting from the specific timeline the two women plan to follow and advance the ongoing course of action (making arrangements). ${ }^{5}$

When 'so' is not used to mark inferential connections, what is it used for? The article argues that, generally speaking, this discourse marker guides the addressee to see the action initiated by the 'so'-prefaced turn constructional unit as having 'emerged from incipiency.' While a default understanding of any utterance is that it advances the

\footnotetext{
${ }^{2}$ Turn constructional units (or TCUs) are syntactically and prosodically complete units of speech (such as, words, phrases, clauses, and sentences) that accomplish a recognizable action given the context of occurrence (Sacks et al., 1974).

${ }^{3}$ For a detailed treatment of sequence organization, see Schegloff (2007).

${ }^{4}$ One apparent exception to this distribution is the case of story tellings (which will be discussed in section 4.2) where a sequence-internal 'so' may be deployed to accomplish story resumption without inferential implications. Story tellings are, however, organized quite differently from other conversational activities (see, e.g., Sacks, 1974).

5 Note that Nancy's 'so' at line 2 does not mark inference from the prior talk and is an example of the target phenomenon. Specifically, here it prefaces a TCU that accomplishes a resumption of a course of action that was introduced earlier but then abandoned (see section 4.2 for further discussion).
} 
immediately preceding talk (Sacks, 1987, 1995), the 'so' preface may be used to suspend that interpretation and characterize the upcoming action as having been 'on the speaker's mind' or 'on agenda' for some time. It should be immediately pointed out, however, that these labels are meant as descriptors of interactional stances participants can adopt and display in talk, and not as direct indices of their cognitive states, intentions, or other internal psychological processes (Heritage, 2005).

The analysis presented in the article aims to demonstrate that 'so' prefacing is used on utterances that launch or pursue courses of action oriented to (by the interlocutors) as enacting their agendas. After a review of relevant literature, I will examine the deployment of 'so' to enact pending agendas and then discuss how it can be used constitutively to characterize a course of action as having been pending.

\section{Prior research on 'so'}

The discourse marker 'so' is commonly understood to have inferential functions. For example, Schiffrin (1987) argues that it has the basic meaning of result (at the discourse level of facts), inference (at the level of knowledge), and actions (as opposed to motives). Additionally, in informal conversation, 'so' can mark "a speaker's readiness to relinquish a turn" and be used to compel a hearer to assume speakership (218). A somewhat similar basic meaning is identified by Blakemore (1988, 2002). Applying Sperber and Wilson's (1986) relevance theory, she maintains that 'so' indicates to the hearer that some kind of inferential connection between the two propositions needs to be made, the nature of the connection to be determined by the hearer.

Raymond (2004) and Local and Walker (2005) present conversation analytic investigations of a special case of 'so' usage: when the discourse marker is deployed as a freestanding unit. Raymond (2004) demonstrates that the stand-alone 'so' is used to prompt a recipient to produce a relevant action (that would in some way acknowledge the action import of the prior turn) by "invoking an upshot that is claimed to be available to a recipient" (211). While this usage of 'so' as a prompt relies on the marker's inferential meaning, Raymond's analysis shows that 'so' invites addressees to make a wide range of connections between the preceding turn and the course(s) of action in which it participates. Raymond shows that the stand-alone 'so' is deployed to manage overlapping contingencies imposed by the turn-taking organization, sequence-organization, and the overall structural organization of conversation as a unit. While Raymond (2004) primarily focuses on sequential aspects of the stand-alone 'so' deployment, Local and Walker (2005) investigate its prosodic features and show that a number of such features differentiate between trail-off and floor holding uses of this marker.

Aside from these studies into inferential 'so,' there has been some documentation of its role in marking other kinds of discourse connections. Howe (1991) appears to be the first one to notice the use of 'so' in topic initial utterances. She argues that, instead of primarily indicating result (as suggested in Schiffrin, 1987), 'so' functions as a "marker of connection" and is used to preface "topic beginners" that resume some not immediately preceding topic or even introduce previously unmentioned topics (93). Further evidence for 'so' use in organizing discourse comes from a comparative study of everyday talk and formal police interviews in England conducted by Johnson (2002). Using quantitative methods, the study documents the use of 'so' for marking topical transitions. Johnson argues that 'so' functions as a "topic developer" or "topic sequencer" deployed in order to focus participants' attention on the interview agenda (103). Johnson's research helps specify connective functions of 'so' by suggesting that only certain kinds of topics - those that implement some interactional agendas - will likely be introduced with this discourse marker.

This brief overview of the literature nearly exhausts all research into the use of 'so' as a discourse marker. ${ }^{6}$ Previous studies of 'so' have left many open issues, especially with regards to how the discourse marker is used in contexts where it does not appear to mark inferential or causal connections. For example, Howe (1991) simply documented the use of 'so' in topic initial utterances without a detailed examination of its interactional functions; Johnson (2002) focused primarily on 'so' in one institutional setting (police interviews) but did not give much attention to its deployment in everyday talk. I attempted to fill some of these gaps in two previous reports where I examined a number of common but under-described usages of 'so.' First, Bolden (2006) compared courses of action prefaced with 'so' to those prefaced with 'oh' and documented that, in ordinary conversation, 'so'-prefacing is overwhelmingly used to

\footnotetext{
6 'So' can also be deployed in a variety of other grammatical functions: for example, as an adverbial modifier (i.e., "he is so nice") or a conjunction ("he took the taxi so as not to be late"). These are beyond the scope of this study (but see, for example, Altenberg, 1984; Ford, 1993; Stenström, 1998).
} 
introduce recipient-attentive matters while 'oh'-prefacing is used with self-attentive matters. Second, Bolden (2008) examined how interlocutors introduce their first conversational topics (such as, their reason for calling), showing that 'so' gets deployed to manage non-routine movement out of conversation openings and into a discussion of the first 'on agenda' item. While these two reports focus on particular contexts of 'so' deployment, this article aims to provide a broad overview of the interactional environments where 'so' is routinely used in order to show that 'so' functions as a marker of 'emergence from incipiency.'

\section{Data and methods}

This study employs the methodology of conversation analysis, which aims to provide a systematic and detailed examination of interlocutors' understandings of the ongoing talk-in-interaction (see, for example, Heritage, 1984b; Sacks et al., 1974). The analysis is based on a data corpus of over $80 \mathrm{~h}$ of recorded and transcribed, naturally occurring casual interactions in American English, both on the telephone and face-to-face. ${ }^{7}$ The data corpus yielded approximately 250 candidate instances of the target phenomenon that were analyzed for this project.

One difficulty in studying discourse markers is in isolating their functions from other interactional phenomena that may be operating simultaneously. In an attempt to overcome this problem, I have investigated, whenever relevant, compatible sequential environments where the discourse marker was not deployed. However, space considerations have prevented me from including many of these comparative analyses into the article (but see Bolden, 2005, 2008).

\section{Using 'so' to implement pending interactional agendas}

The common thread evident in the prior studies of 'connective' 'so's is that this discourse marker prefaces new (or previously abandoned) topics. The question is what kinds of topics are introduced with 'so'? Or, to put it differently, what does 'so' suggest about the upcoming topic? Here, I will demonstrate that 'so' marks the upcoming topic - or, more generally, the upcoming course of action or interactional project - as having been incipient or pending. Specifically, 'so' commonly prefaces turn constructional units that accomplish a shift to what might be considered (and treated by interlocutors) as the pending interactional agenda.

A wide range of issues, topics, or 'mentionables' can be brought up during social encounters. A question ubiquitously oriented to by parties in interaction is 'why that now' (Schegloff and Sacks, 1973) - or, applied to new topic introductions, why is this matter being brought up in this particular interactional context. This means that interlocutors are oriented to providing and finding warrants for raising any particular mentionable. The most common way of bringing up an issue is to fit it to the prior talk (Jefferson, 1978, 1984; Sacks, 1995; Schegloff, 2007; Schegloff and Sacks, 1973). On occasion, however, this may not be a workable or desirable solution (Button and Casey, 1988/ 1989), and something other than prior talk is treated as the warrant for introducing the topic. 'So' prefacing is one practice for showing that the upcoming topic has been prompted not by the immediately preceding talk but by some outstanding conversational agenda. ${ }^{8}$

My analysis indicates that two (related) factors contribute to 'so' prefacing. First, the course of action being launched does not contingently emerge from the immediately prior talk (or other features of context). Second, this course of action is analyzable (by participants and academic onlookers) as having been delayed and, therefore, pending. Put together, these two factors suggest the characterization of 'so' as a marker of 'emergence from incipiency.' In the subsequent two sections I discuss a number of common environments where 'so' is used to preface new and resumed pending interactional agendas.

\footnotetext{
${ }^{7}$ I would like to thank Emanuel A. Schegloff for making a large portion of these data available to me. Other data come from the CallFriend and CallHome corpora collected by the Linguistic Data Consortium of the University of Pennsylvania; parts of the CallFriend corpus are available through the Talk Bank (at www.TalkBank.org).

8 'So' is not the only way to indicate that the upcoming talk is not contingent on what came before. Other English 'misplacement markers' include 'by the way' (Schegloff and Sacks, 1973), 'hey' (Levinson, 1983:313-315), 'listen' (Jefferson, 1972:319), 'look' (Sidnell, 2007), 'now' (Aijmer, 2002), 'okay' (Beach, 1993; Filipi and Wales, 2003), and 'oh' (Bolden, 2006; Jefferson, 1978; Schegloff, 1996). Moreover, several discourse markers can be used specifically to convey the upcoming turn's affinity to some earlier talk: for example, 'anyway' (Ferrara, 1997; Lenk, 1995, 1998; Owen, 1985; Takahara, 1998), 'and' (Heritage and Sorjonen, 1994; Local, 2004), and 'but' (Park, 1997). Amongst these, 'and' might be the closest in function to 'so'; however, more research is needed to explicate relevant 'and' usages in ordinary talk (Bolden, 2007).
} 


\subsection{Warrants for initiating the interaction}

One environment where 'so' is commonly used is with turn constructional units that launch a discussion of the reason behind initiating the encounter - when such discussion has been delayed by some extraneous matters. Ordinarily, the party who initiates an interaction is expected to have some warrant for doing so, either to carry out a specific interactional project or simply to 'catch up' (Button and Casey, 1988/1989). A discussion of any such matters would constitute the conversation's core activity because of the parties' shared expectation that at least some such 'talkable' will at some point be addressed (Schegloff, 1986, 2004). In telephone conversations, the warrant behind initiating the contact is prototypically introduced early in the conversation - immediately after brief openings, in what Schegloff (1986) refers to as the 'anchor position.' On occasion, however, the move to this first talkable is delayed due, for example, to a substantial expansion of the opening, external interruptions, and the like. It is in such environments that we find 'so' prefacing. Here, 'so' prefaces a course of action that has been projected by the very act of initiating the contact (such as, a telephone call) and then delayed. In other words, the discourse marker prefaces a pending course of action that has now 'emerged from incipiency.'

In telephone conversations, one common way to move out of call openings is for the caller to introduce his/her reason for calling - the warrant that prompted the call. When this course of action is postponed in some way, 'so' prefacing is typical. ${ }^{9}$ In Excerpt 3, for example, the reason-for-the-call sequence is delayed by the caller's getting a call on her other telephone line in the very beginning of the conversation before the reason for this call is even brought up. The conversation is between Briar, the caller, and her friend Maya who recently got a new job.

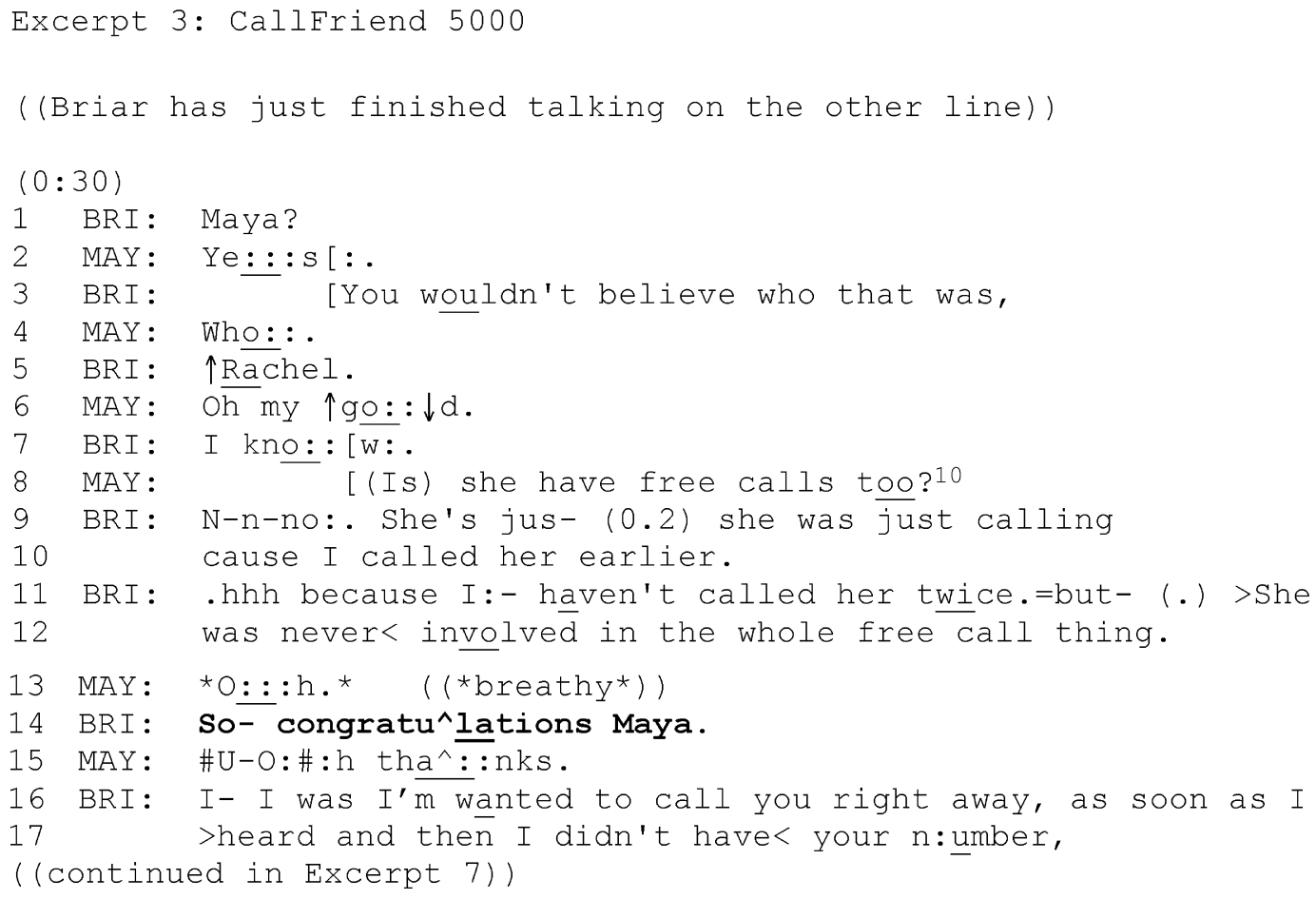

When Briar returns to her conversation with Maya (line 1), the two discuss who it was on the other line (lines 3-13). As soon as that sequence comes to a possible completion (line 13), Briar congratulates Maya on her new job, a course of action hearable as Briar's reason for calling (further confirmed at line 16). Briar's turn is placed not immediately after conversation openings (not recorded), as is typical, but after an incidental sequence (Schegloff, 2007) that has briefly disrupted the routine introduction of the interaction's first talkable. In other words, the course of action thereby launched has been delayed and pending. Furthermore, Briar's subsequent accounting for not calling earlier (lines 16-

\footnotetext{
${ }^{9}$ An extensive analysis of 'so' usage (and non-usage) in this environment can be found in Bolden (2008).

${ }^{10}$ This is in reference to the study through which the phone call was recorded.
} 
17) suggests that, in her view, she should have called earlier, as soon as she heard the news. Thus, there is evidence (from the speaker's conduct) that 'so' prefaces a course of action that has been on the speaker's agenda and pending and which has now 'emerged from incipiency.'

In Excerpt 4, the introduction of the reason for the call is initiated not by the caller (Adam) but by the call recipient (Berta) through a solicitation question. As in the prior segment, the move to discuss the warrant behind the call is delayed by an external intrusion - here the ringing of another phone - and the incidental sequence that emerges from that.

Excerpt 4: CallFriend 5435

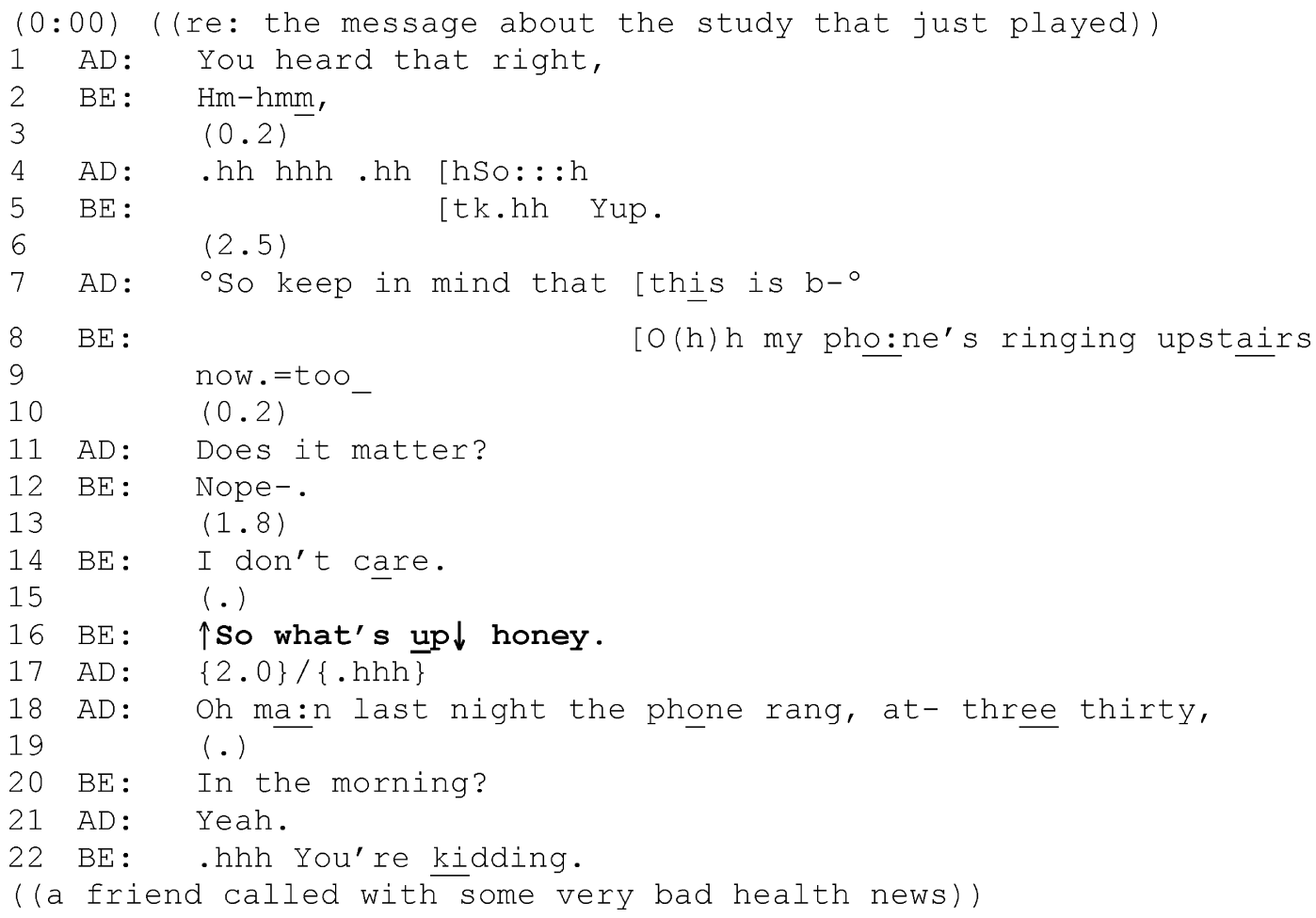

Before Adam and Berta can start talking about what may have prompted Adam's call, Berta remarks that another telephone in her house is ringing (lines 8-9). This noticing launches a brief sequence in which the two parties establish that Berta is not going to answer that phone (lines 8-14). Having brought this incidental sequence to a closure, Berta inquiries into Adam's reason for the call (line 16), prefacing it with 'so.' The inquiry embodies a shift from incidentals to the conversation's core activity, inviting the addressee to introduce a topic that may have warranted the call (which Adam does by embarking on a telling of some traumatic news at line 18). The preface again appears to highlight the delayed, pending character of the action trajectory launched by the question.

As exemplified by the two above segments, when one party launches a reason-for-the-call discussion from a late position, the turn embodying the shift to the interactional agenda recurrently ${ }^{11}$ gets prefaced with 'so.' However, not any sequence launched in this sequential context gets the preface. Occasionally, call recipients unilaterally nominate

\footnotetext{
${ }^{11}$ There are other ways of introducing 'reason for the call' topics from delayed positions that do not involve the use of 'so' prefacing. Space considerations prevent a complete presentation here (see Bolden, 2008), but my investigation of various delayed reason-for-calling introductions suggests that speakers do not use 'so' prefacing when launching 'self-attentive' courses of actions (such as, requesting favors or announcing events in their lives). This finding is consistent with the use of 'so' to mark the upcoming course of action as having been pending and, thus, of special importance to the interlocutors. 'So' prefacing clashes with a minimizing stance typically taken towards self-attentive courses of action (Bolden, 2006). Observe that in both Excerpt 3 and Excerpt 4 'so' is used to introduce an other-attentive course of action: (belated) congratulations and an inquiry into the recipient's reason for calling. Further discussion of this issue can be found in section 5 .
} 
their own topics in this position, and these topic nominations do not get prefaced with 'so.' What does it suggest about 'so'?

To answer the question, let us return to Excerpt 4. In this conversation, the reason-for-the-call sequence (line 16) is delayed by two matters: first, by a discussion of the research study under which the call is being recorded (lines 1-7) and then by the call recipient's announcement that another phone is ringing (lines 8-14). The announcement itself is also in the first topic position and accomplishes a shift from incidentals (such as, the discussion of the research protocol) to some new course of action - a place where other sequences get 'so' prefacing. Here, however, the announcement is prefaced with another discourse marker, 'oh' - a change-of-state token, that marks this as a just-now-noticed event (Heritage, 1984a). Clearly, then, this is not a pending course of action, so we would not expect the 'so' preface to be used here. Thus the differential use of 'so' at these interactional junctures (non-routine transitions out of conversation openings) supports its characterization as a marker of emergence from incipiency. The lack of 'so' prefacing on call recipient's topic nominations reflects the fact that these topics have not been projected from the conversation's start - unlike the initiation of the 'reason-for-the-call' sequences that do get 'so'-prefaced. In other words, 'so' prefacing helps identify the upcoming utterance as advancing the course of action that prompted the conversation as opposed to a line of talk that simply happens to be launched in the 'first topic' position (Schegloff, 1986).

Further evidence that sequence-initial 'so' characterizes a course of action as having emerged from incipiency comes from those cases where this discourse marker alone accomplishes a shift to the conversation's pending agenda. In his analysis of the stand-alone 'so,' Raymond (2004) shows that it functions to prompt the recipient to produce a next relevant action. In cases where the stand-alone 'so' is used to launch a new course of action, it marks "the relevance of known-in-common pending matter for a current sequential environment" (Raymond, 2004:209). For example, in Excerpt 5 below, the call recipient uses the stand-alone 'so' to prompt the caller to introduce her reason for calling. (My analysis here is in close alignment with Raymond's 2004 examination of this segment, pp. 216-217.) Hyla called Nancy to finalize the evening's plans for their theater outing (which she had arranged), as well as to catch up. The first several minutes of the conversation are taken up by a discussion of the day's events. The segment starts with the closing of the discussion of Nancy's visit to a doctor:

Excerpt 5: HG IIa (4-5)

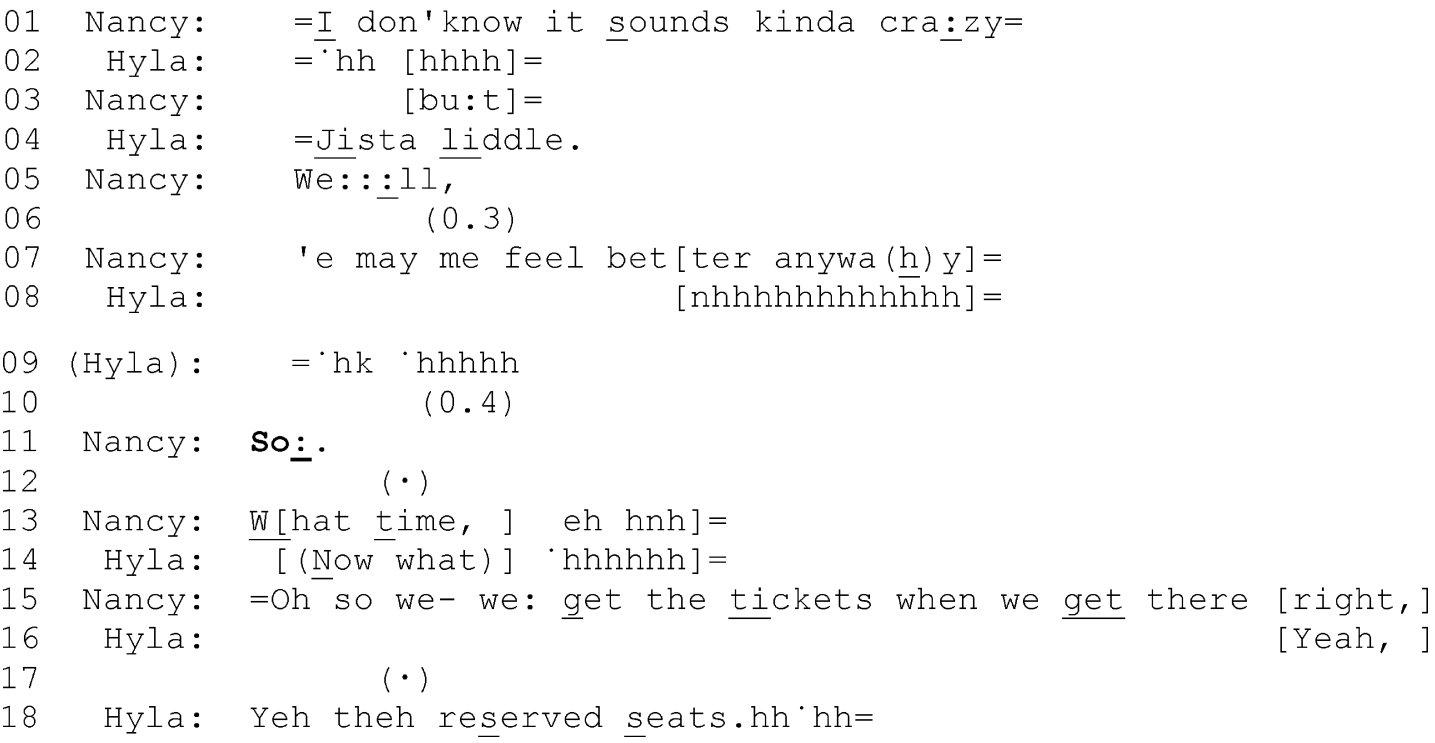

Once the discussion of Nancy's doctor's visit is closed, a gap develops (line 10). This interactional juncture provides space for new matters to be introduced. Rather than launching some course of action explicitly (or continuing to wait for Hyla to launch one), Nancy breaks the gap by producing a stand-alone 'so' (line 11). Unlike the examples we examined earlier, where the 'so'-prefaced turns formulated the action being accomplished, here no clues are provided. In effect, by using the marker alone as a sequence launcher, Nancy invites Hyla to introduce the course of 
action that they both know (and know each other to know) is due. Importantly, the stand-alone 'so' is addressed to the caller, who is also the organizer of the theater trip. Thus, the stand-alone 'so' prompts the caller to initiate a discussion of the pending matter - the caller's reason for calling. The parties' conduct subsequent to the production of the standalone 'so' supports this. Following a short pause (line 12), both Nancy and Hyla simultaneously produce very similar turn beginnings (lines 13-14). While we cannot know where Hyla was going with her turn, Nancy does introduce the pending agenda (the theater trip arrangements) when the overlap is resolved (line 15). Hyla's ready acceptance of this course of action (note her immediate response in 16) suggests that she, too, may have been raising this subject at line 14. All in all, it appears evident that the stand-alone 'so' prompts the launching of a course of action that both parties orient to as having been pending - as well as identifiable on the singular basis of it having been pending. The interlocutors' understanding of the stand-alone 'so' as a prompt to launch a pending course of action supports the analysis of 'so' as a marker of emergence from incipiency and its usage for launching pending interactional agendas. ${ }^{12}$

\subsection{Pursuing interactional agendas}

In addition to prefacing new courses of action, 'so' may be used with turn constructional units that resume an interactional project that was suspended or aborted before coming to completion. One environment that provides a particularly clear illustration of this usage of 'so' is in story-telling episodes. Unlike other instances of 'so' discussed in this article, here the discourse marker is used course-of-action-internally to mark a resumption of the telling after an interruption. 'So'-prefaced turn constructional units often follow narrative segments that interrupt the temporal organization of the narrative (cf. Labov, 1972; Schiffrin, 1987). This discourse marker provides an early characterization of the upcoming TCU as advancing the main story line as opposed to continuing with the parenthetical background segment.

The following excerpt from a dinner conversation between four friends is an illustration of this use of 'so.'

Excerpt 6: Chicken Dinner

(29:00)

((discussing bad restaurant experience the night before))

01 SHA: [Like yih said you ] [wuh feelin $\downarrow$ goo]d, $=$

02 MIC:

03 MIC: ='hhh $\uparrow \underline{M y} \downarrow$ fa:ther we w'r in Manners Big Boy.ih( )

$04 \quad$ Big Bo[y back E]a:st?

05 SHA: [Yea:h? ]

$06 \quad(0.3)$

07 MIC: En eez drinkin a cuppla coffee iss a true story my-

08 (0.2) my $\downarrow$ dad's (0.3) step fathuh eez (0.3) pretty funny

09 $\downarrow$ guy isn'ee ${ }^{\circ}$ (you [know'm) ${ }^{\circ}$

10 SHA: [Uh huh,

$11(0.7)$

12 MIC: Good joke teller evrything so eez (.) drinkin this cup

13 coffee'n there's this $\bar{l}^{\prime} \underline{y}$ un the bottim'ee goes 'hhhhh

14 JEEZIZ CHRI [ST!

15 SHA: [heh-ha ha ha: [ $\left.\begin{array}{lll}h & \mathrm{~h} & \mathrm{~h}\end{array}\right]$

16 MIC: $\quad\left[\right.$ ( $y^{\prime}$ know)] the whole place is

17 (ghho(h)i[ng crhhhz) 'hh He stands up 'hh $\bar{h}(0.2)$ hoh my-

18 VI?: $\quad$ ihh heh-eh

\footnotetext{
12 This analysis is in line with Raymond (2004). The difference is that Raymond treats such cases of stand-alone 'so' as related to the discourse marker's general function to introduce upshots of prior talk (here, marking some sort of inferential connection across conversations) while I relate it to the discourse marker's function to introduce incipient or pending matters. Both analyses agree that 'so' functions by reference to the overall structural organization of a conversation as a unit (Schegloff and Sacks, 1973).
} 
At lines 2-3, Michael launches a story about his father, a story that relates to the four friends' own experience in the restaurant the day before. After an orientation segment in which the setting is introduced (lines 3-4), Michael proceeds with the story. However, following the first TCU ("En eez drinkin a cuppla coffee" at line 7), Michael aborts the forward movement of the narrative to introduce additional background elements (end of line 7 through line 12). This parenthetical is a meta-commentary on the upcoming story: both the nature of the story ("true story") and the character of the protagonist (e.g., "good joke teller"). While these elements are important in orienting the recipients to the story (and assuring its adequate reception upon completion), they do not advance the telling of the story's focal events (or the story's 'complicating action' - Labov, 1972). To return to the main storyline, Michael does an almost exact repetition ${ }^{13}$ of his prior TCU (line 11), prefacing it with 'so' ("so eez (.) drinkin this cup coffee" at lines 16-17). Since the story was not possibly complete at line 11, the resumption of the story was projected by the teller and anticipated by the recipients - in other words incipient.

Aside from advancing suspended story tellings, 'so' is recurrently used with sequence-initial turn constructional units that resume an interrupted action trajectory. The data show that when a course of action has been interrupted or subverted in some way before coming to a possible completion, the turn that invokes the relevancy of this incomplete course of action is commonly prefaced with 'so.' In other words, the discourse marker is, again, used with TCUs that pursue some pending interactional agenda.

One example of this usage of 'so' can be found in Excerpt 7 below, taken from a conversation between Maya and Briar seen earlier (Excerpt 3). Briar recently moved away from her hometown where Maya still lives. Briar calls Maya to discuss Maya's new job, as well as to catch up on other goings-on. However, the course of action initiated by the issuing of congratulations (line 14, further pursued in line 25) is interrupted (line 29). The interruption engenders a topical off-shoot (line 49), and that, in turn, eventuates a discussion of several additional unrelated matters (see line 60; others are omitted for space considerations) - until, finally, the initial course of action is returned to with Maya's 'so'prefaced request to tell about "this exciting new jo:b" (line 74):

\section{Excerpt 7: CallFriend 5000 (continued from Excerpt 3)}

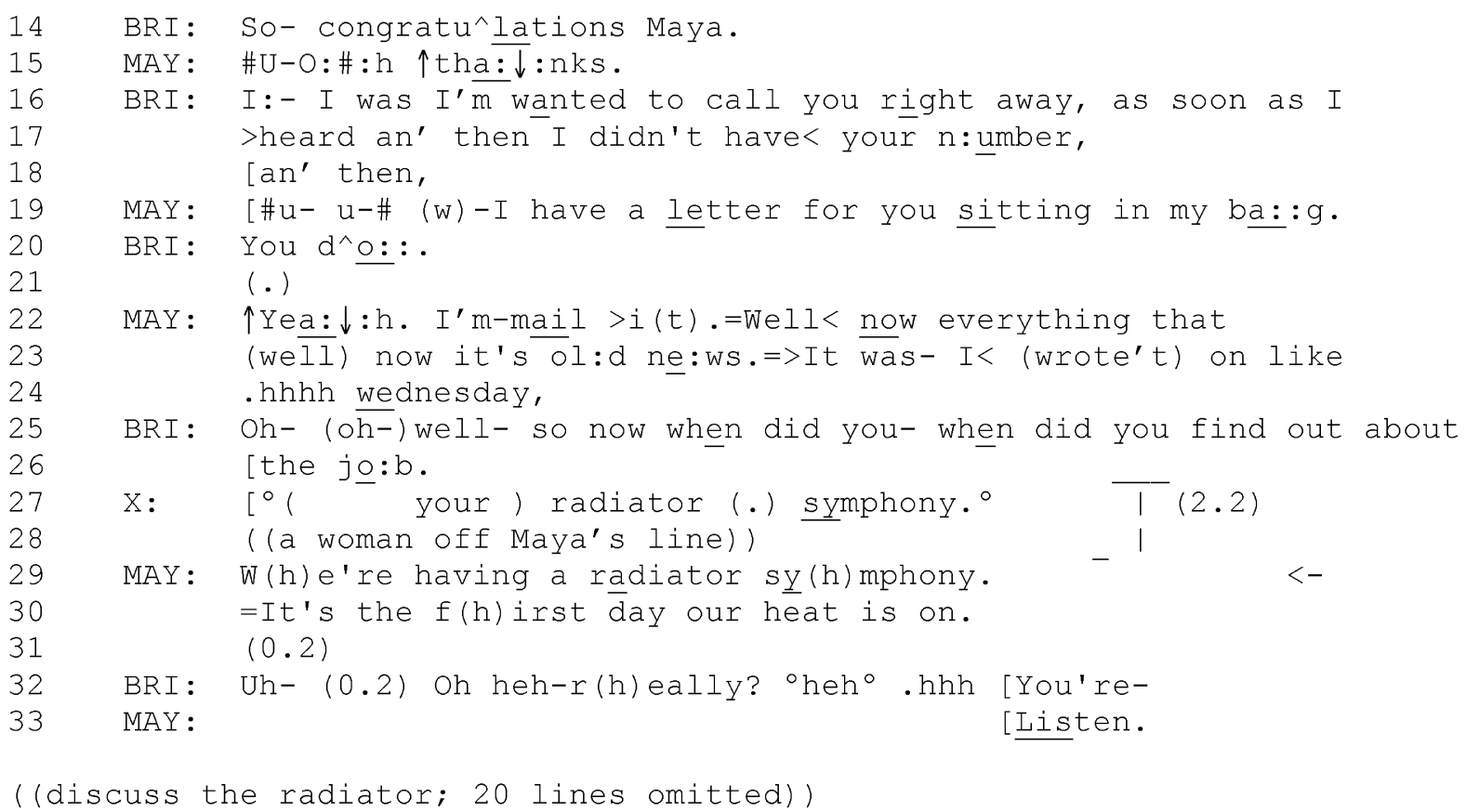

\footnotetext{
${ }^{13}$ Note that a small change is made. Specifically, 'a cup' is replaced with 'this cup.' The substitution serves to connect the current TCU to the first mention of the reference (in line 11), marking it as a non-first saying.
} 


\section{(ldiscuss May's visitor, then another}

MAY: $O: h$ it $w-=$

BRI: =It- [s:u:cks.

MAY: [frossting. [here tolday.] there tonight. .hh $(0.2)$

MAY: Yeah, (.) Yeah. Exactl[y?,

BRI :

I was there though. (0.2) (0.2)

MAY: Ho:w ho:w is it, ?

$$
\text { (.) }
$$

BRI : Um: Good.

MAY: Ye:a[ $\overline{: h}$ ? $(0.5)$

MAY: Uh hu[:h?

$$
\text { (0.5) }
$$

BRI: [But- $[$ ( Jan- $)$

BRI: What?

MAY: Guess who's here tonight?

MAY: This is: so: bizarre. It's really cold here.

BRI: >I ca-< it was like eighty. here today.

BRI: $\quad[I \quad \mid h$ : ] ate it.=I know >my dad said it might-< (0.2) there's a chance that it might s:now up

[HHeh-heh .h I: really wish

BRI: At- in:stead of here. for weather.

BRI: $\quad$ Things are going pretty well I think, .hh (0.2) it's a- a:h. I don't know. I:: (.) $\bar{I}$ feel like I (.) probably

(.) am not doing as much work as I need to be?,

BRI: [but hh ya'know. (.) Those things happen.

MAY: [Who ca: :res.=[Guess wh:o's here tonight. omitted))

64

65

66

67

68

69

70

71

72

73

74

MAY :

hope it's used for research [ ${ }^{\circ}$ purposes $\left.^{\circ}.\right]$

$\left[>W^{\prime}\right] 1 \quad$ I $<$

$\mathrm{BRI}$ : [ I'm hoping ] people

it's- y'know (0.2) publically (.) promoted an' (0.2)

[we sound like] total jerks.

MAY: [Heh-hhh ]

(.)

MAY: Heh-heh-[heh

BRI : $\quad$ That's my hope.

\section{(.)}

BRI: .h[So- tell me about this exciting new jo:b.=

MAY : $\quad[\mathrm{HH}$

BRI: =I- I didn't- Gina gave me: (.) som:e details but I:(.) y'know you know how she is.

MAY: Yea: : h ${ }^{\circ} y^{\prime j} \overline{y^{\prime}}$ know Gina. ${ }^{\circ}=[$. hhh Um: :

BRI :

(.)

[yea:h.

MAY: We: :ll=>I- it's the< Americor' job.

BRI: Right, right.

MAY: and so this week it's all trainning. 
84

85 BRI: Uh- yu- you've started then?

86 MAY: ^Ye:: $\mathrm{s} \cdot=$

((continue about the job))

At lines 25-26, Briar pursues the discussion of Maya's new job with a question that makes a response from Maya conditionally relevant (Schegloff, 2007). Instead of responding to this question, however, Maya reports on an unusual radiator activity in her house (line 29) - a report prompted by what is happening on her end of the telephone line (see line 27). Thus, the discussion of Maya's new job is subverted for the time being. As the conversation unfolds, each time a current sequence comes to a (possible) close, a window of opportunity to return to the topic of Maya's new job opens up. As we follow the conversation, however, we can see that at each point the local exigencies of a particular interactional juncture get addressed, further delaying the return of this pending course of action.

The first opportunity to return to the discussion of Maya's new job occurs around line 49. At line 44, the prior topic (co-complaining about the weather at their two locales) could have been closed with laughter. Brie, however, expands with "II: really wish I was there though." (lines 44-45). This can be understood as a negative assessment of Briar's state of mind regarding her recent move to a new city, so after a short silence, she augments the statement with two increments (Schegloff, 1996, 2000) "in:stead of here. for weather." (line 47). This modified statement can perhaps serve as a sequence-closing summative, bringing the current discussion of weather to a closure. At this point the resumption of the preceding course of action is possible if Briar were to initiate it. Briar, however, does not (see the silence at line 48), and Maya is left to make the next move. Given the complaint-implicative nature of Briar's closing assessment, Maya has little choice but to pursue it, which she does with an inquiry at line 49 ("it" elliptically referring to Briar's life at her new location). So the opportunity to return to the pending "new job" discussion is passed.

A few seconds later, Maya closes the current sequence with "Who ca:::res." (line 60) and immediately rushes to launch a new course of action (by announcing a visitor). The rush-through prevents a reintroduction of the discussion of Maya's new job, indexing, perhaps, Maya's understanding that this new sequence launch is done in place of something else. Several other opportunities to return to the new job discussion are similarly bypassed (not shown) as the parties deal with a variety of local contingencies, till finally, at yet another interactional juncture (see line 74), Briar has an opportunity to resume the course of action that has now been abandoned for several minutes. Observe that the return is accomplished via a "so"-prefaced turn constructional unit that re-proffers the pending topic: "hSo- tell me about this exciting new jo:b." (line 74). The repeat of the keyword "job" (from line 26) helps locate the course of action being returned to and the formulation of the job as "exciting" and "new" re-invokes its initial presentation as something to be congratulated on (congratulations being the course of action Briar uses to introduce the topic at line 14). Thus, the details of turn design serve to reinforce the turn's connection to an earlier part of the conversation, and its sequential placement is consistent with the characterization of 'so' as a marker of emergence from incipiency. Briar then immediately continues her turn to account for not knowing much about the job (by blaming it on Gina; lines 76-77), thus reinforcing this course of action as having been on her 'mind' or 'agenda.'

Interactional projects may span several sequences and get implemented via a sequence of sequences (Schegloff, 2007). One way in which such larger episodes of talk are organized is via a reciprocal sequence of sequences, such as an exchange of 'howareyous' or some other inquiries into each other's lives (Schegloff, 2007). Schegloff (2007) shows that reciprocal sequences are commonly due - and typically take place - immediately upon recognizable possible completion of the first sequence. However, various matters may delay - or even completely derail - the launching of a reciprocal (Schegloff, 2007). It turns out that such belatedly launched reciprocal sequences are regularly prefaced with 'so.' ${ }^{14}$ In Excerpt 8, for example, the reciprocal 'howareyou'-type sequence (line 35) is delayed by an unrelated intervening matter. Arthur calls Rebecca, and the beginning of the conversation is taken up by a discussion of the recording.

\footnotetext{
${ }^{14}$ On occasion, reciprocally positioned 'howareyou' inquiries are not designed as reciprocals (for example, they do not have a stress on 'you') - but are done as if they were 'first' questions (Schegloff, 2007). Interestingly, 'so' is not used to preface such inquiries even when they do not immediately follow the first sequence. The lack of 'so' prefacing in such contexts is consistent with the characterization of 'so' as a marker of 'emergence from incipiency' since such subsequent, yet non-reciprocal 'howareyou's are not treated as advancing a pending agenda but as starting some new, non-incipient matter. This observation emphasizes the flexibility of this interactional resource.
} 
Excerpt 8: Arthur and Rebecca

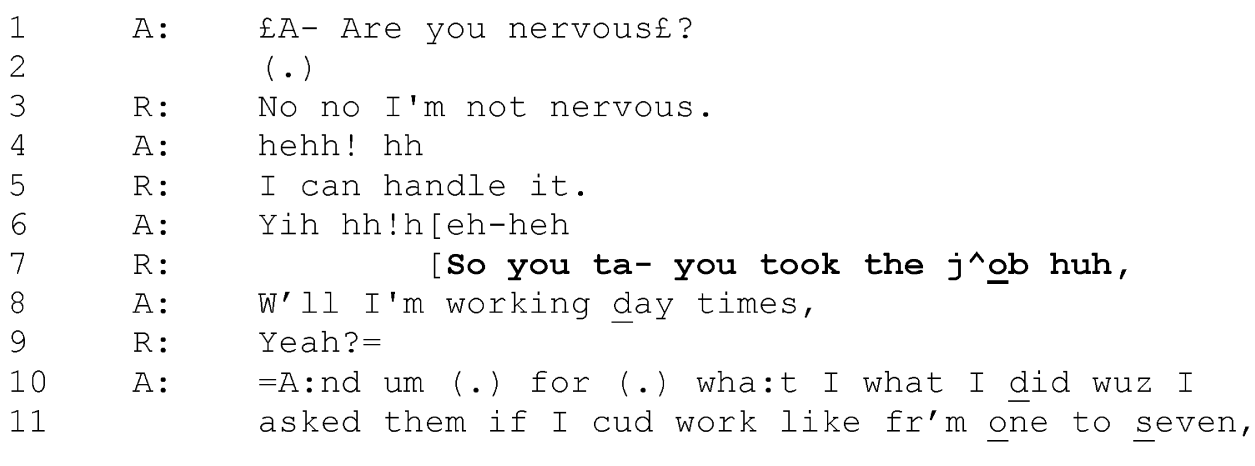

\section{((45 lines omitted))}

$12 \mathrm{~A}$ : s-big (0.2) you know w- (0.6) all these ro:oms,

Having brought the discussion of the recording to a possible completion, Rebecca proffers the first topic - Arthur's new job (line 7). (The 'so' preface on this turn is consistent with the analysis in section 4.1.) The topic of Arthur's job is significantly expanded (for almost $2 \mathrm{~min}$ ). The matter comes to a recognizable possible completion at lines 13,15 , and 18, where Arthur offers a variety of summative characterizations of his job. When Rebecca fails to align with the sequence closure (see the gap at line 19), Arthur continues, adding an increment (Schegloff, 1996, 2000) to his prior turn constructional unit ("> $>$ becuz it's real $<$ "). He then abandons this TCU to launch a new and unrelated topic via an announcement (occasioned, apparently, by his noticing of a bird outside): " $>$ Ya know I g't $<$ humming birds no:w?" (at line 20). The resulting discussion of the humming birds is expanded (see line 31) till, finally, the matter comes to a 
possible completion at lines 33-34. At this point, Arthur brackets the preceding as being 'off-track' with 'anyway' and then launches a 'so'-prefaced 'howareyou'-type inquiry (line 35). The inquiry is done as a reciprocal (note the contrastive emphasis on 'you'). Even though the initial formulation of the question is somewhat generic ("how'r you doin"), the pursuit in line 37 is matched in type to the previous sequence - it is about Rebecca's job experiences.

Thus, we can see that the two sequences (the one launched by Rebecca at line 7 and the one launched by Arthur at line 35) stand in a reciprocal relationship - both proffer the same sort of topic (the job), even though they do it somewhat differently. Arthur's reciprocal inquiry occurs later than it may have been expected: not immediately following the first sequence, but after it was abandoned in favor of an unrelated matter (i.e., the bird feeder). The 'so' preface on the reciprocal inquiry appears to underscore the pending nature of the sequence - as something that has been on the interactional agenda, but has somehow gotten diverted.

Segments presented so far in this section have shown that 'so'-prefaced turn constructional units occur in certain sequential environments and accomplish launching (or extending) courses of action that may be characterized as having been pending. By focusing on the placement of 'so'-prefaced turns, we have evidence of their speakers' orientations to the interactional jobs the preface accomplishes. We have not, however, seen evidence of recipient orientations: While recipients respond in ways that are congruent with the analysis, it has been impossible to show conclusively that they make use of the interactional functions of 'so. ${ }^{15}$ The following segment is a rather rare case where a recipient's understanding of 'so' can be seen in the details of her response to the 'so'-prefaced turn constructional unit.

Excerpt 9 is another segment from the conversation between Maya and her friend Briar (who had moved away). At line 1, Maya initiates a discussion of Briar's new place of residence. Briar mentions her neighbors, which leads Maya to bring up her neighbors (line 37). Maya then prompts Briar to resume talking about her (Briar's) residence, treating her own telling as an interruption. The resumption is accomplished via a 'so'-prefaced prompt "So go ahead," (line 49) - an action that is not fully understood by Briar (line 50):

Excerpt 9: CallFriend 5000

\section{$(6: 00)$}

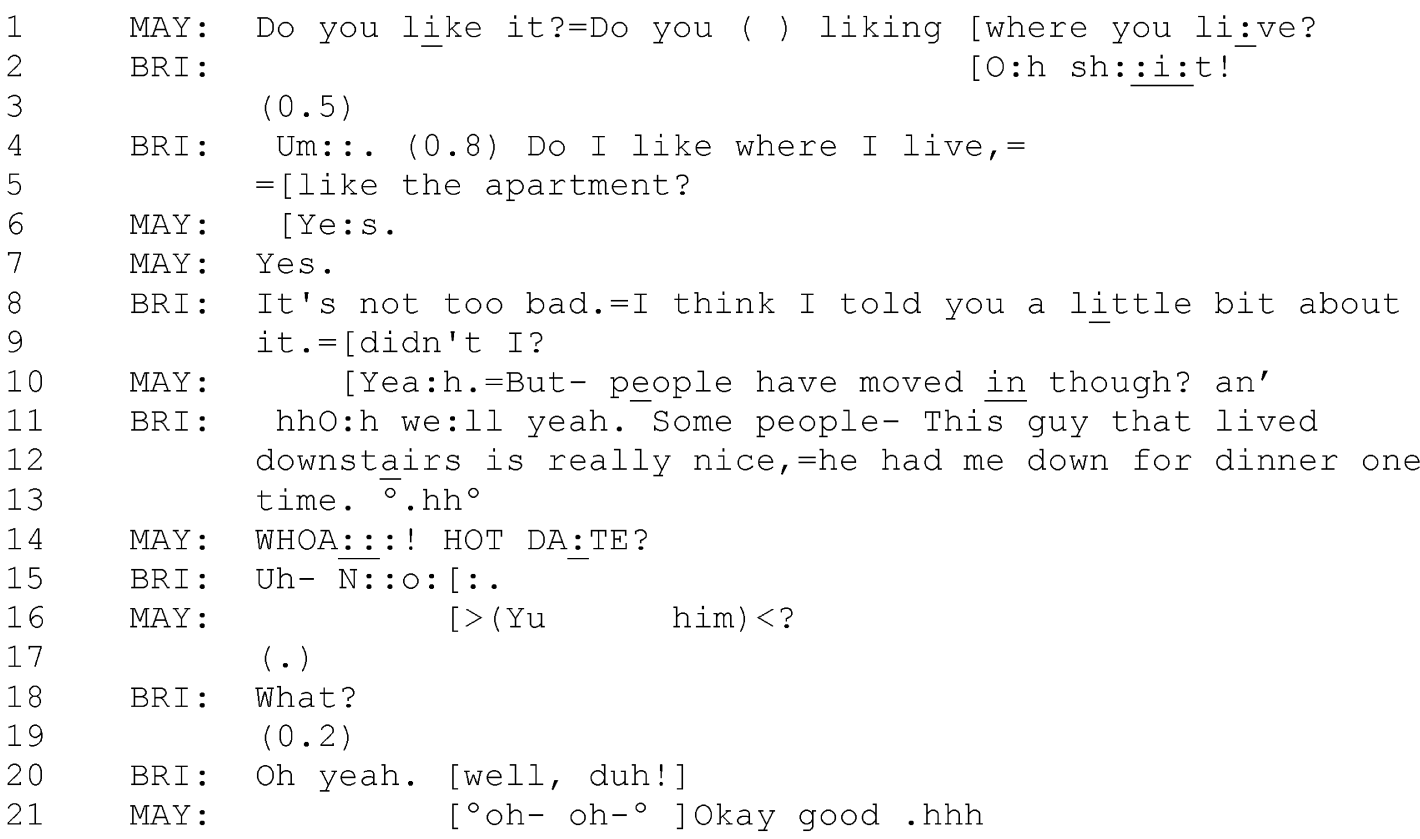

\footnotetext{
${ }^{15}$ This is not an uncommon problem for conversation analysts interested in describing pragmatic functions of particular turn components (such as, discourse markers) since these components are always components of some action - and it is the action recipients respond to, not its individual components. One possible, though not always fruitful, roundabout solution is to compare recipient responses to turns that only differ in the presence/ absence of the target component (see, e.g., Bolden, 2005). Another solution is to examine cases where some problems of speaking, hearing, or understanding reveal interlocutors' understanding of the target component (as done below).
} 


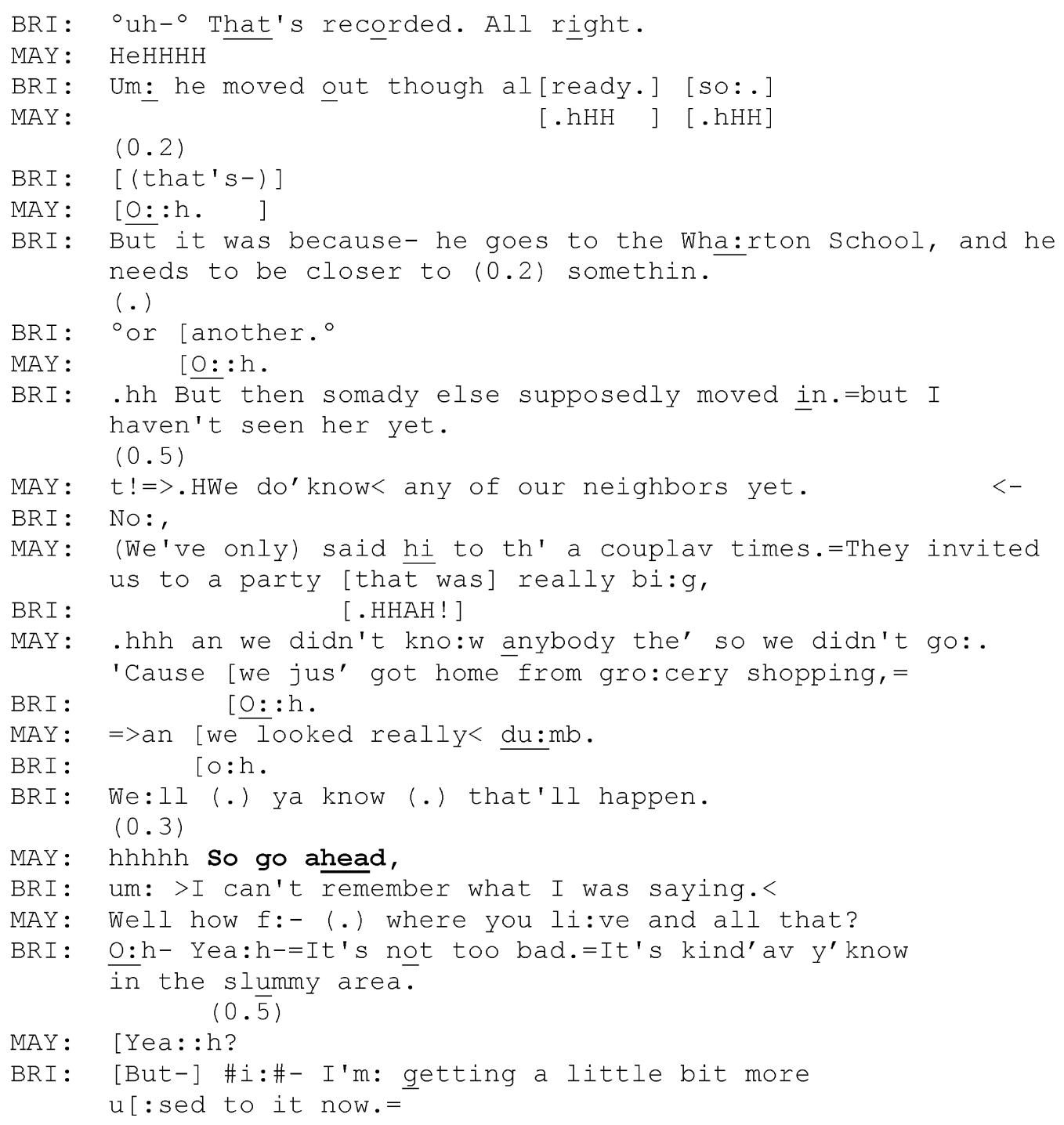

Briar brings a discussion of her neighbors to possible completion at lines 34-35. (Note especially the repeat of "moved in" from Maya's pursuit inquiry at line 10 - a common practice for closing a sequence.) After a gap (line 36), Maya presents her version of the same topic (her own experiences with the neighbors). Briar closes the discussion with a summative uptake of Maya's telling (line 47) and, after a bit of silence, Maya prompts Briar to return to a previously discussed matter with "So go ahead," (line 49). By using this formulation, Maya claims that there is a pending matter to return to and characterizes the preceding talk as an interruption. This underwrites the argument that 'so' is used in environments when some course of action has been pending (albeit in this case, Maya's prompt itself mandates the presence of a pending matter - see the discussion in section 5.2). Interestingly, Maya does not identify what matter should be resumed and puts the onus of figuring it out on the recipient. This proves to be problematic (since there is no obviously pending matter to return to), as evidenced by Briar's response: “um: >I can't remember what I was saying. $<"$ (line 50).

While Briar does not comply with the action of the "go ahead" prompt, her response nonetheless reveals her grasp of this action. Specifically, Briar displays her understanding that she was asked to resume a suspended topic or telling (something she was "saying" earlier, which she now "can't remember"). This understanding appears to rely primarily on the pragmatic function of the "so' preface: an un-prefaced "go ahead" would prompt the recipient to take a turn without indicating what action should be accomplished (and would be quite incongruent in this context). Maya's 
reparative response (line 51) confirms Briar's understanding of "so go ahead" by supplying a missing clue as to what course of action should be continued: Note that "where you li:ve and all that" repeats "where you live" from line 1. In other words, Maya's "so go ahead" was meant to prompt Briar to resume the discussion of living arrangements - a discussion that is claimed to have been pending due to an interruption. Thus, in this case, we have evidence of both interlocutors' understanding of the function of 'so'-prefacing.

To sum, the discourse marker 'so' can be deployed as a preface to turn constructional units that resume pending courses of action. 'So'-prefaced turns resume story-telling episodes and interactional projects that can be seen or claimed as having been prematurely abandoned. In such cases, 'so' characterizes the upcoming action as advancing a pending interactional agenda, alerting the recipient that a pending matter now emerges from incipiency. In the instances analyzed in this section (with the exception of Excerpt 9 as discussed above), the existence of such pending matters is grounded in the organization of conversational activities within social encounters: for example, the expectation that a warrant for the encounter will be discussed or that interactional projects will be carried on to completion rather than abandoned midcourse. In these cases, 'so' highlights for the addressees that a pending or incipient course of action is being implemented, providing an additional cue about how to parse the ongoing stream of talk. However, this discourse marker may also be deployed to characterize a course of action as implementing an incipient agenda where no independent grounds for such claim are evident. I now turn to this constitutive usage of 'so.'

\section{Using 'so' to constitute interactional agendas}

The discourse marker 'so' can be employed to convey to the addressee that a course of action accomplished by the current turn constructional unit should be understood as emerging from incipiency in contexts where no shared expectation for a relevancy of a particular action at a particular interactional moment may be apparent in place. So, while in the examples discussed in section 4 the speaker and (on some occasions) the recipients can be seen as sharing an orientation to a particular action as having been relevantly missing and now emerging from incipiency, here I turn to cases where no such orientation is evident. Essentially, the speaker capitalizes on the function of 'so' to introduce incipient projects in order to suggest to the addressee that, even though it has not been evidently pending, the course of action should still be understood as advancing the interactional agenda. In other words, the speaker may use the 'so' preface constitutively to propose a particular warrant for launching the sequence.

The discourse marker 'so' may be used constitutively in two broadly defined environments. First, it may be deployed with new (for the current conversation) courses of action, marking them as having been on the 'agenda.' Second, it may be used with resumptive courses of action, prefacing turn constructional units that foreground a course of action that was possibly complete and moved away from. The deployment of 'so' in these two contexts is discussed below.

\subsection{Launching new courses of action}

As discussed in section 4.1, the 'so' preface is recurrently used on utterances that launch new interactional projects (such as warrants for making a telephone call), marking them as having been incipient. While the incipient status of these action trajectories can, in some contexts, be attributed to their demonstrably delayed placement in the conversation, it may also derive largely (or even solely) from the 'so' preface itself. In other words, speakers draw on this discourse marker's capacity to mark upcoming matters as having been incipient to propose a particular interpretation on the action they are about to launch. Interestingly, 'so'-prefaced courses of action are overwhelmingly (and practically without exception) 'other-attentive' - i.e., they display the speaker's knowledge of or interest in the addressee's life (Bolden, 2006). This suggests that speakers can mark certain courses of action as incipient not (only) for reasons of managing discourse coherence (i.e., for showing how this action 'fits' with what has come before) but in order to enact recipient-involvement.

The discourse marker 'so' may be used to preface turn constructional units that proffer a variety of topics, ${ }^{16}$ such as specific ongoing events in the addressee's life. The following segment (Excerpt 10) is taken from a

\footnotetext{
${ }^{16}$ For an examination of topic proffering, see Schegloff (2007).
} 
dinnertime conversation between a married couple, Mark and Kim. Mark manages a restaurant and had brought home some sample ravioli to try out. The excerpt takes place soon after they sit down to dinner and starts with a discussion of the ravioli they are eating. After a long pause (line 7), Mark inquires about a "skit" Kim had at work (line 8):

\section{Excerpt 10: Ravioli Dinner}

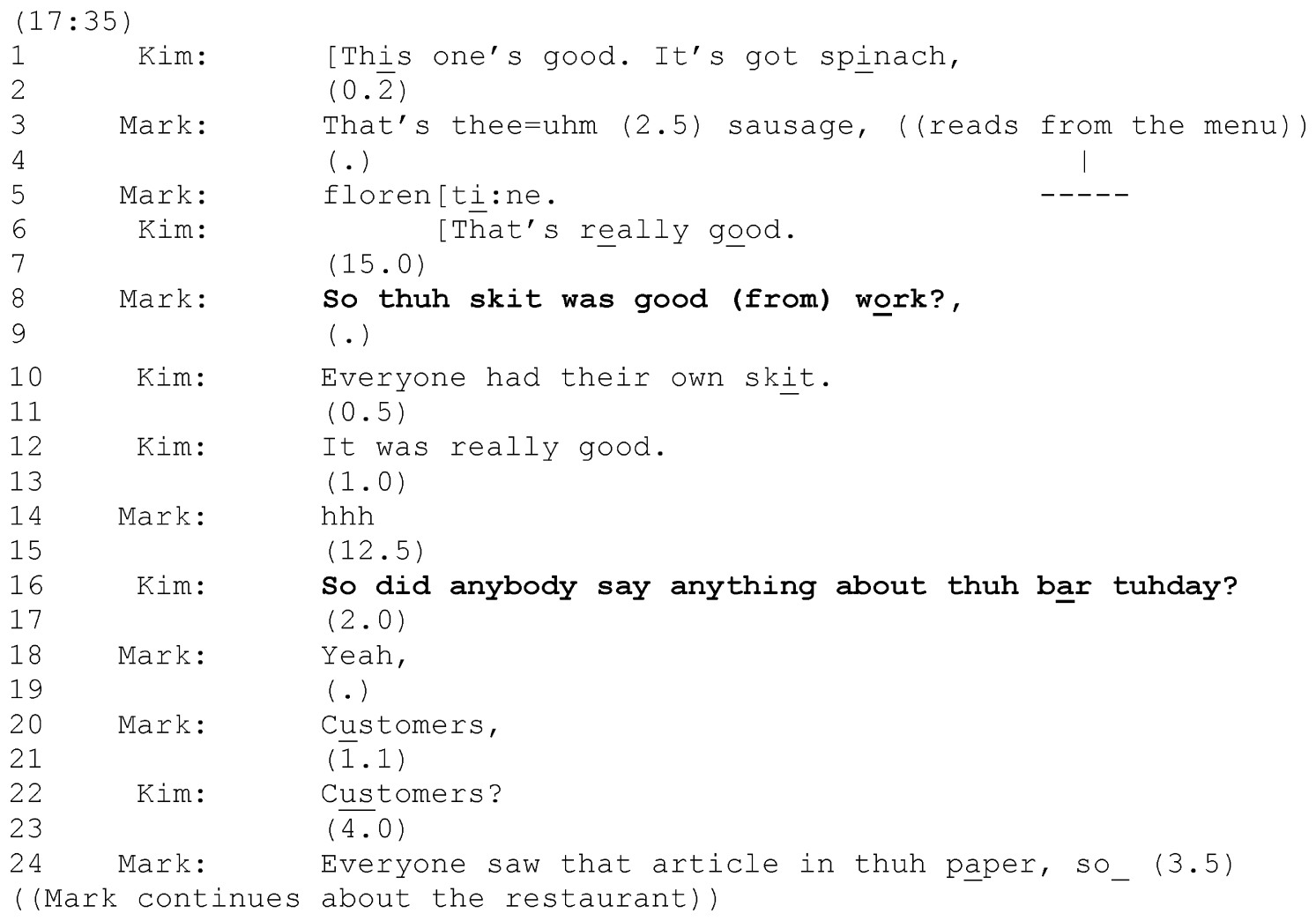

Mark's 'so'-prefaced inquiry at line 8 is a disjunctive topic proffer that shifts the conversation from one activity (food appreciation) to another (current events in each other's lives). Kim at first embraces the topic (line 10), but when Mark fails to follow through (see the gap on line 11), the sequence gets closed (line 12). Following a long gap (during which the food is being consumed - line 15), Kim proffers another topic - a reciprocal inquiry into the day's events at Mark's workplace, a topic that is embraced and expanded (line 24). Both sequences thus emerge from a lull in the conversation, breaking very long gaps (taken up by food consumption). Notably both issues address something the two parties know about the other, requesting updates on ongoing matters. Specifically, these inquiries are formulated in such a way as to show the 'known-in-common' status of what is being brought up. For example, "the skit" (line 8) is a rather minimal reference that underscores its recognizability for the participants, and Kim's inquiry (line 16) invokes - but does not formulate - a specific piece of news that people at Mark's restaurant may be talking about. Thus, by proffering these specific topics, each speaker shows that s/he knows (and remembers) the goings-on in the other person's life, inviting the other to provide an update on the issue (cf. "tracking" inquiries discussed in Morrison, 1997). It appears that by prefacing these updating questions with 'so,' the speakers use its function as a marker of emergence from incipiency reflexively to indicate that the matter is something they had meant to raise, thus emphasizing their engagement with the addressee (see Bolden, 2006 for an extended discussion of this usage).

The next segment shows that speakers may overtly characterize 'so'-prefaced topics as having been incipient. In Excerpt 11, the 'so'-prefaced new sequence initiator follows a search for a topic. The search explicitly formulates 
the new issue as something the speaker wanted to inquire about, thus indicating the 'on agenda' character of the upcoming matter.

Excerpt 11: CallFriend 4984

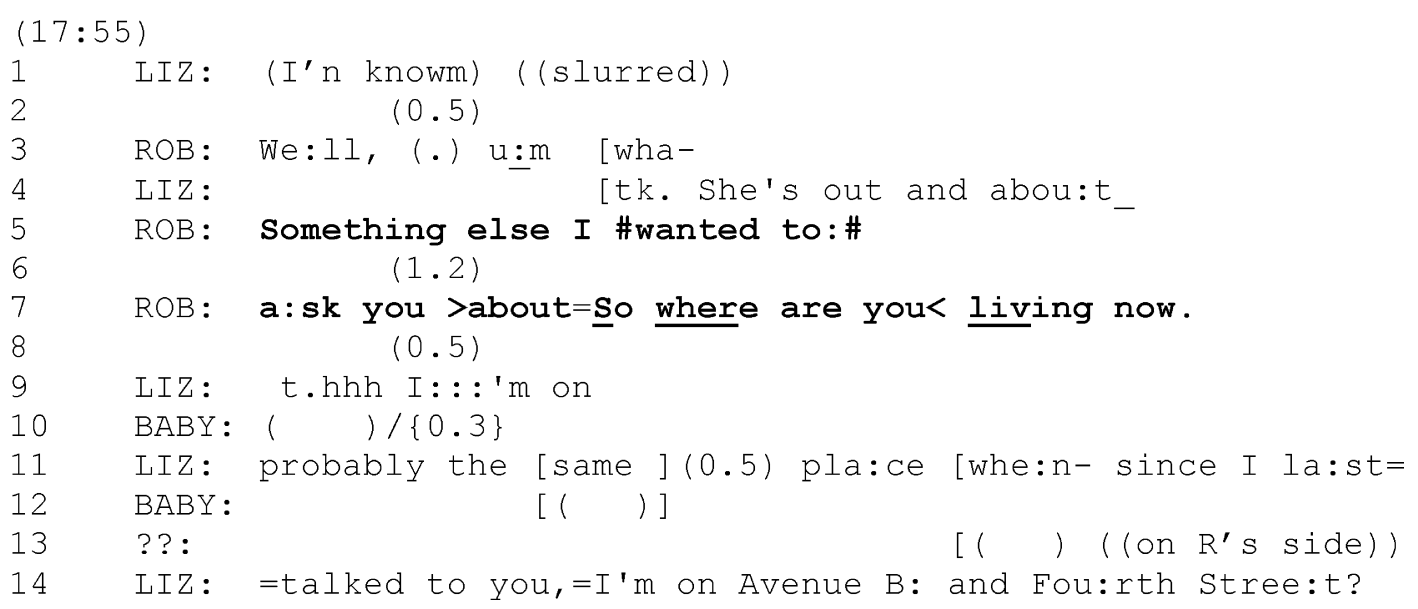

As the prior topic comes to a close (not shown), Roberta initiates a move to a new matter. She starts with a search (at line 3) that Liz interrupts to re-close the preceding sequence (line 4). Roberta then restarts the search for a new topic by explicitly stating that there is something else she'd like to discuss (lines 5-7). When that turn constructional unit approaches the place of possible completion (at 'about'), the speaker rushes to initiate a new sequence (requesting an update on the addressee's living situation), prefacing it with 'so' (line 7). Observe that the inquiry invokes a 'known-in-common' fact about the recipient (i.e., that Liz has recently moved), thereby alluding to the interlocutors' shared interactional history. (Interestingly, Liz's answer at lines 9/11/14 is formulated precisely by reference to this issue.) Here, the speaker's explicit characterization of the upcoming matter as having been on her agenda lends further support to the analysis of 'so' as a marker of emergence from incipiency.

The examples in this section illustrate the fact that 'so' may be used with turn constructional units that launch new interactional projects, such as topic proffers. Typically, they appear at a place where a prior course of action has come to a possible completion and nothing else is immediately launched. An interlocutor uses this conversational lull as an opportunity to launch a new action trajectory, implementing a shift to what can be perceived (and occasionally explicitly characterized) as an 'on agenda' inquiry. My analysis of a larger collection of cases (from which the examples presented here are drawn) demonstrates that 'so' is only used to launch other-attentive courses of action, suggesting that speakers may rely on the function of 'so' to introduce incipient actions in order to achieve particular interactional payoffs (Bolden, 2006).

\subsection{Reopening closed action trajectories}

As we saw in section 4.2, the discourse marker 'so' is recurrently deployed to advance interactional projects that were suspended or aborted before coming to possible completion. As it turns out, 'so' may also be used to return to and reopen action trajectories that, for all practical purposes, could have been considered closed. The use of 'so' in these contexts is again constitutive. By using the 'so' preface, the speaker conveys to the addressee that the course of action should be understood as advancing the conversation's pending agenda. Similarly to the cases in section 5.1, 'so' is found to preface turn constructional units that advance other-attentive action trajectories.

The discourse marker 'so' may be used on follow-up inquiries that resume a previously closed course of action after a substantial delay. Excerpt 12, taken from a dinner conversation between two hosts (Jim and his wife Leni) and their three guests (Joe, Edith, Sam), illustrates this usage. At the beginning of the segment (line 1), Jim initiates a new sequence - a complaint about having been unable to get in touch with one of the guests: 
Excerpt 12: Schenkein II

$(13: 15)$

1 Jim:

2 Edith:

3 Jim:

4 Edith:

5 Joe:

6

8
9
10

Joe:

Jim:

Sam:

Jim:

Joe:

Sam:

Joe:

Jim:

Edith:

Joe:

Edith:

Jim:

( ) :

Joe:

Edith:

Sam:

Edith:

Joe:

Edith:

Sam:

(Joe):

Jim:

(Sam):

Jim:

Jim:

Sam:

Joe:

Sam:

Jim:

Leni:

Edith:

Leni:

Edith:

Joe:
I tried tuh call you by the way.

Yea $[:: \mathrm{h}$ ? [I think ih $\mathrm{w}^{\prime} \mathrm{z}$ Thursday, you weren' in.

Thurs [dee?

[No.
(She $\mathrm{w}^{\prime} \mathrm{z}$ [gone).

[(No. Sam.) I taw- I talked to you on Thursday,

[Me?

[ I tried tuh talk tuh sam on Thursday

but he wasn' [home

[Well he probly went for a wah-=

$$
[1
$$

=no he went for a walk.

(1.5)

Ih musta [been a long walk

[That $w^{\prime} z$ on Friday.

Y'know where 'e walked?

That $w^{\prime} z$ on Fridee he went fer the long walk.

Where didje go.

[No, Thursdeh-

$\left[\begin{array}{ll}( & )\end{array}\right)$

$\left[\left(\begin{array}{ll}( \\ (1)\end{array}\right)\right.$.

$\left[\left(\begin{array}{ll}( & \end{array}\right)\right.$.

[( Friday, Friday yeah.)

( [ ),

[From duh hass to the Chinese theetuh.

Uh!

$\underline{\text { Really }}$ ?

[( (clatter) )

$\left[\begin{array}{ll}( & {[}\end{array}\right]$

Gee that's good (for yuh).

Took me en ar.

That's good.

$(1.0)$

I wen' (en back)

Didje go t'the movies?

( [ in there?)

[Mhhh

Oh you put the cheese in there. That's (where they were.) okay, ( $\quad$ )

I went- I, went to, uh Escon[dido Friday.

((about 5 minutes omitted))

$(19: 00)$ 
Jim's complaint about not being able to get through on the phone gets corrected as it turns out that he has been trying to reach Sam (see lines 11-12) and not Joe and Edith (his parents) as it was initially understood. Joe offers an account for Sam not being there to answer the phone (lines 13-15): Sam went for a walk. While this account turns out to be incorrect (the walk was not on the day in question - see line 18), it nevertheless becomes topicalized (line 19), and a discussion of Sam's “long walk" ensues. (Sam is elderly, so a long walk is made into a big deal.) At line 29, Sam conveys that he walked to the Chinese Theater (in Hollywood). The sequence is brought to a possible completion at around line 37. Jim then reopens the subject with a follow-up question (at line 40). However, the question seems to only get a non-verbal response (or no response at all ${ }^{17}$ ), and very quickly (by line 46), the parties are on to another subject.

Approximately $5 \mathrm{~min}$ go by, during which several other issues are addressed, but at line 48, Jim uses a gap in the conversation to return to the topic of Sam's walk. The return is done via a 'so'-prefaced statement that reiterates what had already been established: that Sam walked to the Chinese Theater (note the word repeats of "Chinese Theater" and "walk"). The statement serves as an other-attentive topic proffer, and the interlocutors embrace the topic and resume the discussion of Sam's walk. Here the topic has not been pending as it had apparently been brought to a possible completion. The 'so' preface used on this turn constructional unit characterizes the implemented action as having been incipient, however, and the word repeats serve as clues as to the source of the sequence initiation. This allows the interlocutors to place the sequence by reference to prior talk.

Another common environment for 'so' prefacing is in 'next topic' solicitations - utterances that invite the addressee to introduce another topic for discussion (such as, "(So) what else is going on?"). In telephone conversations, next topic solicitations (also known as "topic initial elicitors") usually take place in contexts where conversation closings can be relevantly initiated (Button and Casey, 1984). Used to generate new topics, topic solicitations are common in interactions where the participants' agenda consists of getting updated on the events in each other's lives. In Excerpt 13, for example, the two parties first discuss travel plans for the upcoming visit, but then the caller (Calvin) moves on to solicit a next topic (line 8). After the topic introduced in response runs its course, the caller produces yet another topic solicitor (line 30) - and the 'so' preface is deployed in both cases.

Excerpt 13: CallFriend 5051 (extended Excerpt 1)

\section{$(1: 50)$}

((discuss travel arrangments for C's visit))

1 RIC: ^Yeah.

$$
(1.8)
$$

CAL: So what else is going on down there.

RIC: A:hm just watchin Johnny Cochoran.

$$
(0.2)
$$

RIC: smoo: :ze the: (0.8) the- uh jury.

$(0.5)$

CAL: Ye::s, but he's guilty. ${ }^{\circ}$ (Broke it). ${ }^{\circ}$

RIC: [You think-

\footnotetext{
${ }^{17}$ Unfortunately, no video record is available. Since the subject of what movie Sam may have seen at the movie theater does not come up again, it is likely that Jim's question was answered negatively with a non-vocal signal.
} 


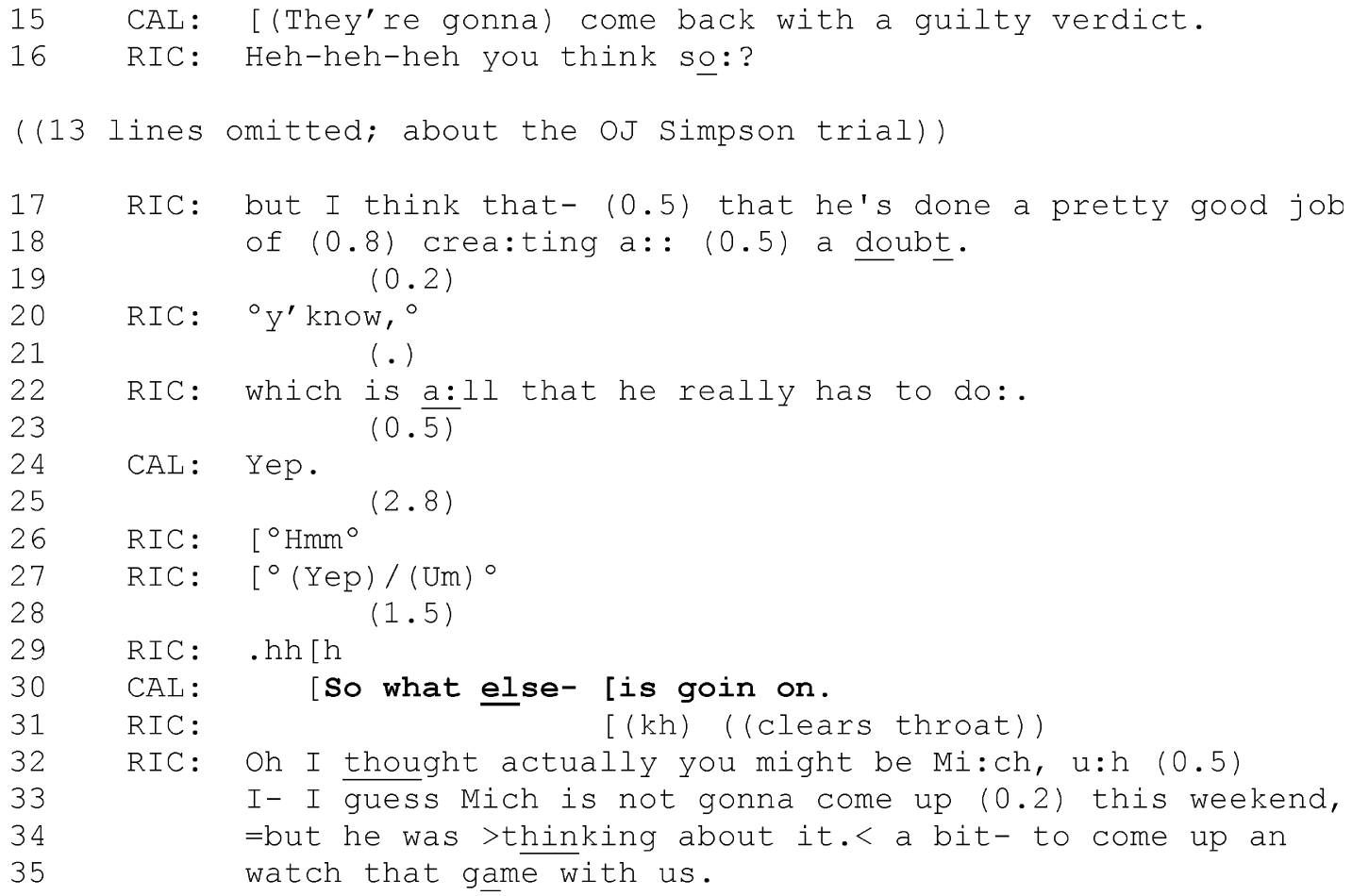

This conversation is ostensibly made to discuss the caller's travel plans. However, when that course of action is closed (line 6), and following a long gap (line 7), the caller attempts to solicit a next topic by inquiring into the recent events in the Rick's life. The topic solicitation (line 8) is prefaced with 'so.' Given the use of 'so' prefacing for introducing pending matters, its presence here marks the inquiry as having been incipient (something Calvin had meant to inquire about) and suggests that, while the first topic (travel arrangements) may have been one reason for the call, it was not the only one. In response to the question, Rick comes up with a topic (the O.J. Simpson trial), and some discussion ensues.

After the topic is closed (at line 24), the conversation stalls (lines 25-28), making an entry into conversation closings possible again. However, after quite a bit of silence, Calvin produces another topic solicitation (line 30), almost entirely repeating his first inquiry (at line 8). Again, the 'so' prefacing on the question suggests that the caller is advancing the agenda for the call, and the open-ended question design indicates that it pursues a nomination of the next topic (which Rick does at lines 32-35). ${ }^{18}$ Thus, in both cases, 'so' prefaced turn constructional units serve to reopen the 'getting updated' action trajectory.

In addition to prefacing generic topic solicitations, 'so' may also be used to preface sequences that advance a specific interactional program. The examples will be taken from one phone call dedicated to a single, though multifaceted topic. The conversation is between two women, Fanny and Yolla, one of whom (Yolla) has just given birth and is still in the hospital. Yolla's birth experiences, her plans regarding childcare, and a variety of related matters are the topics the other woman proffers throughout the conversation. Many of these topic proffers are 'so'-prefaced to mark them as having been 'on agenda' for the conversation. ${ }^{19}$

Fanny, the caller, indicates her reason for calling when she congratulates Yolla in the beginning of the conversation, after discussing the conditions under which the call is recorded.

\footnotetext{
${ }^{18}$ It should be noted that the research protocol for this conversation indicates that it should be at least 10 min in length to qualify for a monetary compensation, so the caller has an independent motivation to keep the conversation going beyond the first couple of minutes where the arrangements for his upcoming visit are discussed.

${ }^{19}$ It might be relevant to note that both women speak a New York Jewish dialect, and it has been observed that in this dialect "connective "so", is particularly widespread (e.g., Benor, 2004).
} 


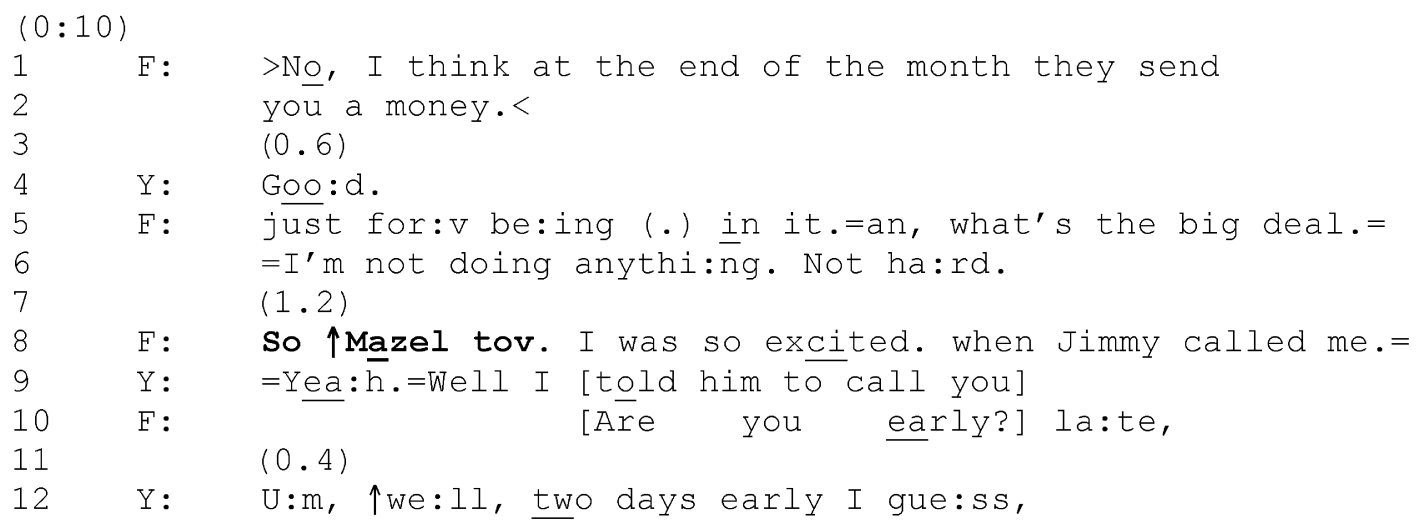

The reason for Fanny's call is introduced via 'so'-prefaced congratulations. This usage of 'so' for prefacing a pending warrant for calling was examined in section 4.1 (see, especially, Excerpt 3). Here, the congratulations set up the interactional agenda for the call - an agenda that is pursued throughout the 30-min conversation. After discussing Yolla's childbirth experiences, Fanny brings up another aspect related to the conversation's agenda - Yolla's plans for the near future:

Excerpt 15: CallFriend 4889

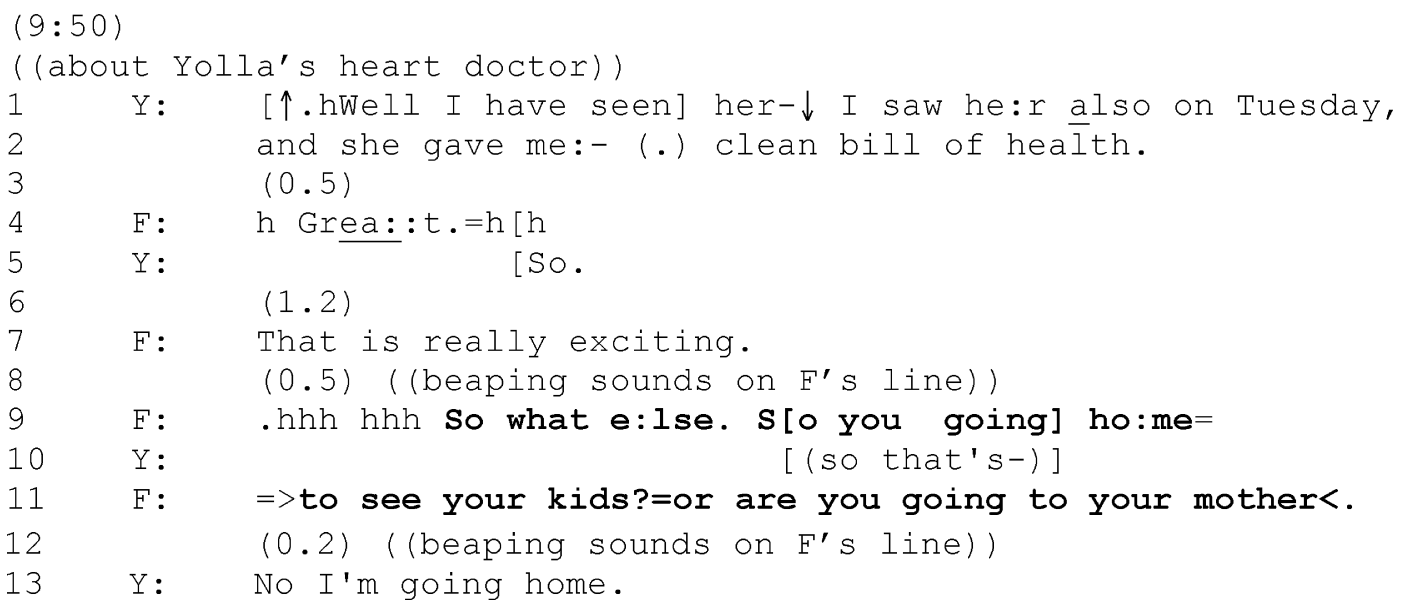

When the two women close the discussion of Yolla's health prior to the childbirth (at lines 4-5, for example), the conversation stalls (see the gap at line 6). Fanny then provides a generic summative regarding the matter at large at line 7, and then another gap is allowed to develop (line 8). At this point, the conversation closure could be initiated, but instead Fanny moves the conversation forward by first doing a generic topic solicitor ("So what e:lse" at line 9) and then quickly reformulating it as a topic proffer ("So you going ho:me >to see your kids?=or are you going to your mother<" at lines 9/11). The proffered topic continues to deal with the conversation's agenda (the birth of the child and its implications), and 'so' - notably present in both versions of the inquiry underscores this.

A few minutes later, Fanny and Yolla are discussing Yolla's childcare plans. When the topic is closed (and after dealing with her own children), Fanny introduces yet another related matter - the reaction of Yolla's husband, Yimmy, to having a new baby: 


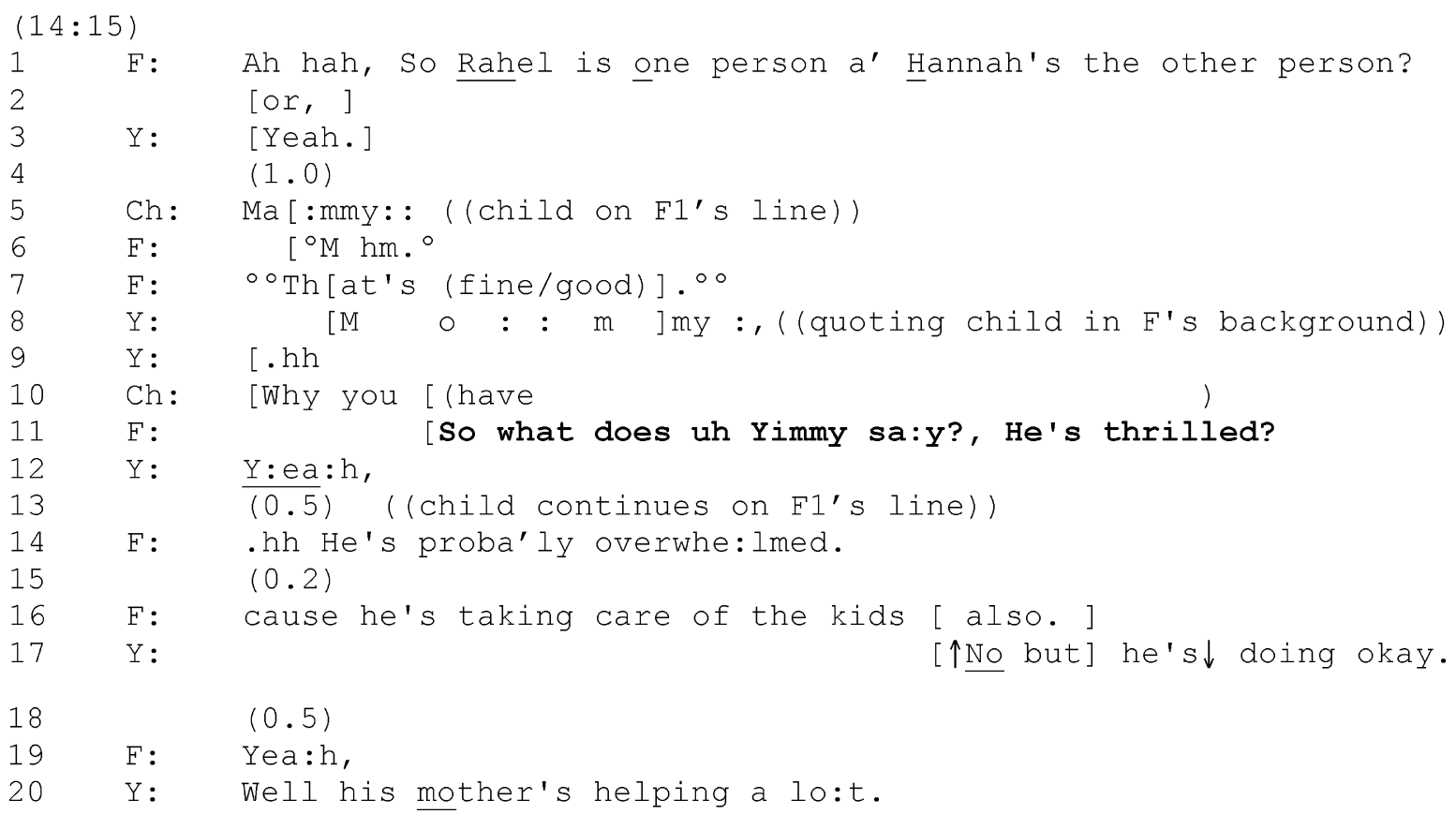

The topic proffer at line 11 is designed as a 'so'-prefaced, wh-interrogative, soon reformulated into a yes/no question. It shifts the conversation from an incidental sequence (dealing with the interrupting child on Fanny's side) to the conversation's core project - a discussion of Yolla's childbirth experiences. After some resistance to the stance conveyed by the topic proffer, Yolla embraces the topic (line 17) and further talk ensues. Fanny's question (line 11) is again marked as having been 'on agenda' with the 'so' preface. ${ }^{20}$

Thus in each case, the 'so'-prefaced inquiry proffers a topic related to the overall agenda for the conversation discussing Yolla's childbirth. These topic proffers follow conversational lulls (in the form of silences or incidental sequences). Unlike those cases where the interactional agendas have been suspended or aborted before coming to completion and where 'so'-prefaced turns are used to resume pending business (as in Excerpt 6 through Excerpt 8), here the conversation could be closed at each point where the 'so'-prefaced utterance is deployed. 'So' serves to mark these topic proffers as advancing the topical agenda for the conversation even though it could be considered completed. Observe also that in each case the course of action being advanced is addressee-attentive.

Overall, in addition to prefacing matters that are oriented to as pending by both interlocutors, 'so' can be used to introduce or further advance courses of action that may not, from the point of view of the recipients, be pending. In such contexts, the speaker proposes a particular understanding of the upcoming course of action with the 'so' preface, indicating to the interlocutor that the issue has been on his/her agenda and now emerges from incipiency. The data show that 'so'-prefaced turn constructional units advance courses of action that are recipient- (rather than self-) attentive. This suggests that speakers may use 'so'-preface not only to indicate relationships between sequences and courses of actions but also to highlight their interest or concern for the addressee.

\section{Conclusion}

The article has specified pragmatic functions of the 'connective' 'so' in English conversation. The focus has been on sequence-initial 'so's - that is 'so's deployed as a preface on turn constructional units that initiate various courses of action. With the exception of story-telling episodes, it appears that it is this sequential placement that distinguishes

\footnotetext{
${ }^{20}$ Further instances of 'so'-prefaced topic proffers related to the childbirth discussion are found in this conversation but omitted in the interests of space.
} 
such usages of 'so' from inferential ones. The general argument has been that 'so' conveys to the addressee that the upcoming course of action is emerging from incipiency and has been on the interactional agenda. In other words, 'so' is one solution available to the interlocutors for dealing with a common interactional problem: how to show that the current utterance is occasioned by something other than the immediately preceding talk. 'So' helps answer the question 'why that now' by instructing the recipients to understand the current turn by reference to some pending interactional agenda. Thus, this discourse marker is a resource for establishing discourse coherence and, more fundamentally, accomplishing understanding.

I have examined a number of environments where 'so' is deployed. 'So' prefacing is recurrently used in contexts where a particular course of action is oriented to by the interlocutors as having been pending or relevantly missing. For example, 'so' is used as a preface to turn constructional units that launch a discussion of the warrant that prompted the interaction (such as, the caller's reason for calling) when some other matter has put off its timely introduction. Additionally, 'so' prefacing is deployed on turn constructional units that pursue abandoned or interrupted interactional projects. In these environments, some interactional agendas are evidently and manifestly pending, and 'so'-prefaced utterances are used to advance them. However, speakers may also use the preface to constitute a course of action as having been incipient or 'on agenda' when no structural warrant for such a claim is apparent. For instance, 'so' can be used to launch new courses of action (such as updating sequences) that have not been demonstrably pending. Additionally, 'so'-prefaced turn constructional units may reopen action trajectories that have been brought to completion and all but forgotten. By using 'so' constitutively, speakers license the launching (or re-launching) of a particular course of action by reference to some interactional agenda. Notably, only recipient-oriented courses of action receive 'so' preface, which suggests that speakers may use it for particular interpersonal goals (such as, to enact other-attentiveness).

Characterizing 'so' as a marker of 'emergence from incipiency' is an attempt to account for a large variety of 'so' usages while being as specific about its functions as possible. Overall, this study advances prior research into the deployment of 'so' without denying the validity of earlier findings. For example, the article specifies Howe's (1991) overly generic description of 'so' as a "marker of connection" by detailing the types of connections this discourse marker indexes and in what sequential contexts. The article also extends Johnson's (2002) view of 'so' as a 'topic developer" that advances institutional agendas by explicating how 'so' is deployed in its home environment mundane conversations. Methodologically, the findings presented here underscore the importance of examining discourse markers within action sequences as well as within larger stretches of talk. The examination of 'so' has shown that a discourse marker's functioning may be tied to its position within the sequence and the position of the sequence within larger interactional projects carried out by participants in conversation (cf. Raymond, 2004).

\section{Acknowledgements}

Many thanks go to Manny Schegloff, who has contributed in numerous and invaluable ways to this research project. I would also like to thank the journal's editors and referees for their insightful comments and suggestions.

\section{References}

1983. Longman Dictionary of American English. Longman, White Plains, NY.

1995. Collins COBUILD English Dictionary. Harper Collins, London.

Aijmer, Karin, 2002. English Discourse Particles: Evidence From a Corpus. John Benjamins, Philadelphia.

Altenberg, Bengt, 1984. Clausal linking in spoken and written English. Studia Linguistica 38, $20-69$.

Beach, Wayne A., 1993. Transitional regularities for casual 'Okay' usages. Journal of Pragmatics 19 (4), $325-352$.

Benor, Sarah Bunin, 2004. Salience and ideology in adults' acquisition of second dialects. Paper presented at the Linguistic Society of America, Boston.

Blakemore, Diane, 1988. 'So' as a constraint on relevance. In: Kempson, R.M. (Ed.), Mental Representations: The Interface Between Language and Reality. Cambridge University Press, New York, pp. 183-195.

Blakemore, Diane, 2002. Relevance and Linguistic Meaning: The Semantics and Pragmatics of Discourse Markers. Cambridge University Press, New York.

Bolden, Galina B., 2005. Delayed and incipient actions: the discourse markers "-to" and "so" in Russian and English conversation. Unpublished Doctoral Dissertation, Applied Linguistics, University of California, Los Angeles.

Bolden, Galina B., 2006. Little words that matter: discourse markers "so" and "oh" and the doing of other-attentiveness in social interaction. Journal of Communication 56 (4), 661-688. 
Bolden, Galina B., 2007. And-prefaced questions in everyday conversation. Paper Presented at the 2007 Annual Conference of the National Communication Association, Chicago, Illinois.

Bolden, Galina B., 2008. So what's up?": using the discourse marker "so" to launch conversational business. Research on Language \& Social Interaction 41 (3), 302-327.

Button, Graham, Casey, Neil, 1984. Generating topic: the use of topic initial elicitors. In: Atkinson, J.M., Heritage, J. (Eds.), Structures of Social Action. Cambridge University Press, Cambridge, pp. 167-190.

Button, Graham, Casey, Neil, 1988/1989. Topic initiation: business-at-hand. Research on Language and Social Interaction 22, 61-92.

Ferrara, Kathleen, 1997. Form and function of the discourse marker anyway: implications for discourse analysis. Linguistics 35 (2), $343-378$.

Filipi, Anna, Wales, Roger, 2003. Differential uses of okay, right, and alright, and their function in signaling perspective shift or maintenance in a map task. Semiotica 147 (1(4)), 429-455.

Ford, Cecilia E., 1993. Grammar in Interaction: Adverbial Clauses in American English Conversations. Cambridge University Press, Cambridge.

Heritage, John, 1984a. A change-of-state token and aspects of its sequential placement. In: Atkinson, J.M., Heritage, J. (Eds.), Structures of Social Action: Studies in Conversation Analysis. Cambridge University Press, New York, pp. 299-345.

Heritage, John, 1984b. Garfinkel and Ethnomethodology. Polity Press, New York.

Heritage, John, 2005. Cognition discourse. In: Te Molder, H., Potter, J. (Eds.), Conversation and Cognition. Cambridge University Press, Cambridge, pp. 184-202.

Heritage, John, Sorjonen, Marja-Leena, 1994. Constituting and maintaining activities across sequences: and-prefacing as a feature of question design. Language in Society 23 (1), 1-29.

Howe, Mary Locke, 1991. Topic change in conversation. Unpublished PhD Dissertation, Department of Linguistics, University of Kansas.

Jefferson, Gail, 1972. Side sequences. In: Sudnow, D.N. (Ed.), Studies in Social Interaction. Free Press, New York, pp. 294-338.

Jefferson, Gail, 1978. Sequential aspects of storytelling in conversation. In: Schenkein, J. (Ed.), Studies in the Organization of Conversational Interaction. Academic Press, New York, pp. 219-248.

Jefferson, Gail, 1984. On stepwise transition from talk about a trouble to inappropriately next-positioned matters. In: Atkinson, J.M., Heritage, J. (Eds.), Structures of Social Action: Studies in Conversation Analysis. Cambridge University Press, New York, pp. 191-222.

Johnson, Alison, 2002. So . . ?: pragmatic implications of so-prefaced questions in formal police interviews. In: Cotterill, J. (Ed.), Language in the Legal Process. Palgrave Macmillan, New York, pp. 91-110.

Labov, William, 1972. The transformation of experience in narrative syntax. In: Labov, W. (Ed.), Language in the Inner City: Studies in the Black English Vernacular. University of Pennsylvania Press, Philadelphia, pp. 354-396.

Lenk, Uta, 1995. Discourse markers and conversational coherence. In: Wårvik, B., Tanskanen, S.-K., Hiltunen, R. (Eds.), Organization of Discourse: Proceedings from the Turku Conference, University of Turku, Turku, pp. 341-352.

Lenk, Uta, 1998. Marking Discourse Coherence: Functions of Discourse Markers in Spoken English. Gunter Narr Verlag, Tübingen, Germany.

Levinson, Stephen C., 1983. Pragmatics. Cambridge University Press, New York.

Local, John K., 2004. Getting back to prior talk: and-uh(m) as a back-connecting device in British and American English. In: Couper-Kuhlen, E. (Ed.), Sound Patterns in Interaction: Cross-linguistic Studies of Phonetics and Prosody for Conversation. John Benjamins, Amsterdam, pp. 377400.

Local, John K., Walker, Gareth, 2005. Methodological imperatives for investigating the phonetic organization and phonological structures of spontaneous speech. Phonetica 62, 120-130.

Morrison, Jody D., 1997. Enacting involvement: some conversational practices for being in relationship. Unpublished PhD Dissertation, Temple University, Philadelphia.

Ochs, Elinor, Schegloff, Emanuel A., Thompson, Sandra A., 1996. Interaction and Grammar. Cambridge University Press, Cambridge.

Owen, Marian, 1985. The conversational function of "anyway". The Nottingham Linguistic Circular 14, 72-90.

Park, Yong-Yae, 1997. A cross-linguistic study of the use of contrastive connectives in English, Korean, and Japanese conversation. Unpublished PhD Dissertation, Applied Linguistics, University of California, Los Angeles.

Raymond, Geoffrey, 2004. Prompting action: the stand-alone "so" in ordinary conversation. Research on Language and Social Interaction 37 (2), $185-218$.

Sacks, Harvey, 1974. An analysis of the course of a joke's telling in conversation. In: Bauman, R., Sherzer, J. (Eds.), Explorations in the Ethnography of Speaking. Cambridge University Press, Cambridge, pp. 337-354.

Sacks, Harvey, 1987. On the preferences for agreement and contiguity in sequences in conversation. In: Button, G., Lee, J.R.E. (Eds.), Talk and Social Organization. Multilingual Matters, Philadelphia, pp. 54-69.

Sacks, Harvey, 1995. Lectures on Conversation. Blackwell, Cambridge, MA.

Sacks, Harvey, Schegloff, Emanuel A., Jefferson, Gail, 1974. A simplest systematics for the organization of turn-taking for conversation. Language 50, 696-735.

Schegloff, Emanuel A., 1986. The routine as achievement. Human Studies 9 (2-3), 111-151.

Schegloff, Emanuel A., 1996. Turn organization: one intersection of grammar and interaction. In: Ochs, E., Schegloff, E.A., Thompson, S.A. (Eds.), Interaction and Grammar. Cambridge University Press, Cambridge, pp. 52-133.

Schegloff, Emanuel A., 2000, November. On turns' possible completion, more or less: increments and trail-offs. Paper Presented at the 2000 Annual Conference of the National Communication Association, Seattle, Washington.

Schegloff, Emanuel A., 2004. Answering the phone. In: Lerner, G.H. (Ed.), Conversation Analysis: Studies From the First Generation. John Benjamins, Philadelphia, pp. 63-107.

Schegloff, Emanuel A., 2007. Sequence Organization in Interaction: A Primer in Conversation Analysis. Cambridge University Press, Cambridge.

Schegloff, Emanuel A., Sacks, Harvey, 1973. Opening up closings. Semiotica 8 (4), 289-327.

Schiffrin, Deborah, 1987. Discourse Markers. Cambridge University Press, Cambridge. 
Sidnell, Jack, 2007. 'Look'-prefaced turns in first and second position: launching, interceding and redirecting action. Discourse Studies 9 (3), 387408.

Sperber, Dan, Wilson, Deirdre, 1986. Relevance: Communication and Cognition. Blackwell, Cambridge.

Stenström, Anna-Brita, 1998. From sentence to discourse: Cos (because) in teenage talk. In: Jucker, A.H., Ziv, Y. (Eds.), Discourse Markers: Descriptions and Theory. Benjamins, Amsterdam, Netherlands, pp. 127-146.

Takahara, Paul O., 1998. Pragmatic functions of the English discourse marker anyway and its corresponding contrastive Japanese discourse markers. In: Jucker, A.H., Ziv, Y. (Eds.), Discourse Markers: Descriptions and Theory. Benjamins, Amsterdam, Netherlands, pp. 327-351.

Galina B. Bolden (PhD, University of California-Los Angeles) is an Assistant Professor at the Department of Communication, Rutgers University. Her research focuses on studying everyday talk-in-interaction in English and Russian languages, both in ordinary and institutional settings. 